\title{
A Discussion of Inner South Projection Angle for Performance Analysis of Dielectric Compound Parabolic Concentrator
}

\author{
Xu Yu, Yuehong Su* \\ Institute of Sustainable Energy Technology, Department of Architecture and \\ Built Environment, University of Nottingham, University Park, NG7 2RD, UK \\ * Corresponding author. Tel.: +44 115 8467872; fax: +44 1159513159. \\ E-mail address: yuehong.su@nottingham.ac.uk
}

\section{ABSTRACT}

In the performance analysis of a trough compound parabolic concentrator (CPC), the concept of south projection angle is often used for the nonmeridional sunlight to compare with the acceptance angle of CPC to determine if solar radiation could be collected. The solar altitude and azimuth are the only two factors used to calculate the south projection angle. However, for the solid CPC made of dielectric material, due to the refraction on the air-dielectric interface, the optical path of refracted light within a dielectric CPC would also depend on the refractive index of dielectric material and the tilt angle of CPC. The conventional south projection angle would not be suitable for performance analysis of a solid dielectric CPC. This paper therefore introduces a concept of inner south projection angle which is based on the refracted light and derives a formula using vector analysis. The formula relates the inner south project angle with the solar altitude and azimuth, the refractive index, and the CPC tilt angle as well. Photopia software is meanwhile employed to predict the optical performance of dielectric CPC. The simulation results confirm that use of the inner south projection angle can determine if solar radiation could be collected or transmitted through a dielectric CPC rather than conventional south projection angle. Discussions are given about the correlation between the inner south projection angle and the optical efficiency and transmittance of a trough dielectric CPC. This provides a convenient way to evaluate the performance of a dielectric CPC over a period such as a whole year. 
Keywords: outer and inner south projection angle; dielectric Compound Parabolic Concentrator (dielectric CPC); angular optical performance; vector calculation

\begin{tabular}{|c|c|c|c|}
\hline \multicolumn{4}{|c|}{ Nomenclature } \\
\hline$A B C D$ & $\begin{array}{l}\text { Interface between air } \\
\text { and dielectric material }\end{array}$ & $\theta_{\text {half }}$ & $\begin{array}{l}\text { Inner half acceptance } \\
\text { angle }\end{array}$ \\
\hline CPC & $\begin{array}{l}\text { Compound Parabolic } \\
\text { Concentrator }\end{array}$ & $\begin{array}{l}\theta_{i} \\
\theta_{i}^{\prime}\end{array}$ & $\begin{array}{l}\text { Incidence angle } \\
\text { Refraction angle }\end{array}$ \\
\hline \multirow{3}{*}{$\begin{array}{l}\mathrm{CPC}-4 \\
\mathrm{EW} \\
n \\
\mathrm{NON}^{\prime}\end{array}$} & $\begin{array}{l}\text { CPC with geometrical } \\
\text { concentration ratio of } 4\end{array}$ & $\Delta \theta_{i}$ & $\begin{array}{l}\text { Angle between incident } \\
\text { light and refracted light }\end{array}$ \\
\hline & $\begin{array}{l}\text { East-west } \\
\text { Refractive index } \\
\text { surface normal of plane }\end{array}$ & $\theta_{N S}$ & $\begin{array}{l}\text { Outer south projection } \\
\text { angle of incident solar } \\
\text { radiation }\end{array}$ \\
\hline & $A B C D$ & $\theta_{N S}^{\prime}$ & Inner south projection \\
\hline \multirow{4}{*}{$\begin{array}{l}\mathrm{NS} \\
\mathrm{OS}_{1} \\
\mathrm{OS}_{1}{ }^{\prime} \\
\mathrm{R} \\
\mathrm{R}_{\mathrm{p}}\end{array}$} & North-south & & angle of refracted solar \\
\hline & Refracted sunlight & & radiation \\
\hline & $\begin{array}{l}\text { Extension of line } O S_{1} \\
\text { Surface reflectance }\end{array}$ & Subscripts & \\
\hline & $\begin{array}{l}\text { Reflectance for } \mathrm{s}- \\
\text { polarized light } \\
\text { Reflectance for } \mathrm{p} \text { - } \\
\text { polarized light }\end{array}$ & a & $\begin{array}{l}\text { Light path with } \\
\text { refraction angle smaller } \\
\text { than the inner half } \\
\text { acceptance angle }\end{array}$ \\
\hline \multirow{2}{*}{$\begin{array}{l}\mathrm{R}_{\mathrm{S}} \\
\mathrm{S} \\
\mathrm{S}_{1}{ }^{\prime}\end{array}$} & Solar position & b & Light path with \\
\hline & $\begin{array}{l}\text { Equivalent sun position } \\
\text { for light path within the } \\
\text { dielectric CPC }\end{array}$ & & $\begin{array}{l}\text { refraction angle larger } \\
\text { than the inner half } \\
\text { acceptance angle }\end{array}$ \\
\hline \multirow[t]{2}{*}{$\mathrm{SNS}_{1} \mathrm{~N}_{1}$} & Surface consists of & $\mathrm{x}$ & South-north horizon \\
\hline & $\begin{array}{l}\text { incident and refracted } \\
\text { Sunliaht }\end{array}$ & $\begin{array}{l}y \\
z\end{array}$ & $\begin{array}{l}\text { East-west horizon } \\
\text { Zenith }\end{array}$ \\
\hline so & Incident sunlight & & \\
\hline \multicolumn{2}{|c|}{ Greek Letters } & & \\
\hline \multirow{3}{*}{$\begin{array}{l}\beta \\
\gamma \\
\gamma^{\prime}\end{array}$} & Tilt angle of dielectric & $\vec{n}$ & $\begin{array}{l}\text { Normal vector of surface } \\
\mathrm{SNS}_{1} \mathrm{~N}_{1}\end{array}$ \\
\hline & $\begin{array}{l}\text { CPC } \\
\text { Solar azimuth angle }\end{array}$ & $\overrightarrow{N O}$ & $\begin{array}{l}\text { Normal vector of surface } \\
A B C D \text { (unit vector) }\end{array}$ \\
\hline & $\begin{array}{l}\text { Equivalent solar } \\
\text { azimuth angle for }\end{array}$ & $\overrightarrow{O S_{1}}$ & $\begin{array}{l}\text { Vector of refracted light } \\
\text { (unit vector) }\end{array}$ \\
\hline \multirow{2}{*}{$\begin{array}{l}\theta_{h} \\
\theta_{h}{ }^{\prime}\end{array}$} & Solar altitude angle & $\overrightarrow{S O}$ & $\begin{array}{l}\text { Incident sunlight vector } \\
\text { (unit vector) }\end{array}$ \\
\hline & $\begin{array}{l}\text { Equivalent solar altitude } \\
\text { angle for refracted } \\
\text { sunlight }\end{array}$ & $\overrightarrow{S_{1}^{\prime} O}$ & $\begin{array}{l}\text { Vector of equivalent sun } \\
\text { position (unit vector) }\end{array}$ \\
\hline
\end{tabular}




\section{Introduction}

In the development of solar energy technologies, one research focus is to collect the solar energy more effectively (Sellami and Mallick, 2013). Solar concentrator is one typical technology which uses optics with specific shape and material to concentrate the solar energy for PV or solar thermal application. The compound parabolic concentrator (CPC) is one kind of non-imaging low concentration solar concentrator. In recent years, CPC and its variations like lens-walled CPC ( $\mathrm{Li}$ et al., 2013), symmetrical or asymmetrical dielectric CPC (Mallick et al., 2006), etc. have been extensively studied for concentrating PV application. The advantages of CPC include relatively simple structure, no need of complex and expensive sun-tracking system, reduced solar cell area per unit output for PV application and reduced cost of the system (Yu et al., 2014b).

The dielectric compound parabolic concentrator (dielectric CPC) is an alternative to the mirror CPC. Its enlarged acceptance angle due to refraction on airdielectric interface could help to collect solar radiation from wider sky angles, and the total internal reflection could minimize the reflection loss on the CPC lateral wall (Pei et al., 2012). Additionally, the property of transparent dielectric material also makes it suitable for the building-integrated application such as building façade. Zacharopoulos et al. (Zacharopoulos et al., 2000) and Mallick et al. (Mallick and Eames, 2007) investigated the optical performance of both symmetric and asymmetric truncated non-imaging dielectric low-concentration concentrators for building façade application and presented some attractive features for PV application. Sabry et al. studied a PV-integrated dielectric CPC for transparent façade and elevated the influence of truncation percentage on the collective efficiency and concentration ratio of CPC (Sabry et al., 2013). The authors' recent research has discussed that the dielectric CPC has the potential for combined application of PV electricity generation and seasonal daylighting control due to its unique angular optical feature (Yu et al., 2014a).

The angular performance of a two-dimensional CPC is the basis to determine the performance of a trough CPC under a sky (Rönnelid et al., 1997, Gordon et 
al., 1996). For an east-west orientated trough CPC, the solar radiation projected on the north-south meridian is the only component could be collected by the CPC and its altitude angle is the so-called south projection angle. In the previous research of various CPC variations under real sky condition, the south projection angle is widely used to determine the effective collection of direct component of solar radiation and the optical performance of CPC (Pei et al., 2012, Li et al., 2013). However, we have found that the south projection angle is not really precise enough to be used for nonmeridional rays on a dielectric CPC due to refraction on the air-dielectric interface. This issue had been initially discussed by Welford and Winston, who mentioned the actual acceptance angle of a dielectric CPC needs to be adjusted by a certain degree for nonmeridional rays (Welford and Winston, 1978). Instead, the presented study introduces the concept of inner south projection angle which corresponds to the refracted light within the dielectric CPC and calculates it using vector calculation, while the conventional one may be called outer south projection angle. The formula of the inner south projection angle will be given in terms of sun position and dielectric CPC properties, and the difference between the outer and inner south projection angles will be discussed for a dielectric CPC of various tilt angles for selected location. The correlation between the optical performance of dielectric CPC and the inner south projection angle will be also given.

\section{Concept of south projection angle}

\subsection{South projection angle}

In the research of solar energy, if a solar collection device faces south, it would provide convenience in analysis to divide the solar position vector into two orthogonal components, i.e., one in the east-west direction and one in the north-south direction as shown in Fig. 1. As the component in east-west direction is parallel to the solar collection surface, it does not contribute to the overall solar collection onto the device, while the component in the north-south direction determines the solar collection. The south projection angle is therefore 
defined as the angle between the south horizon and the projection of the solar position vector on the north-south meridian plane ( $\theta_{N S}$ in Fig. 1). Its value can be calculated according to the solar altitude $\theta_{h}$ and solar azimuth $\gamma$ using Equation 1 (Su et al., 2012b).

$$
\tan \theta_{N S}=\frac{\sin \theta_{h}}{\cos \theta_{h} \cos (180-\gamma)}=-\frac{\tan \theta_{h}}{\cos \gamma}
$$

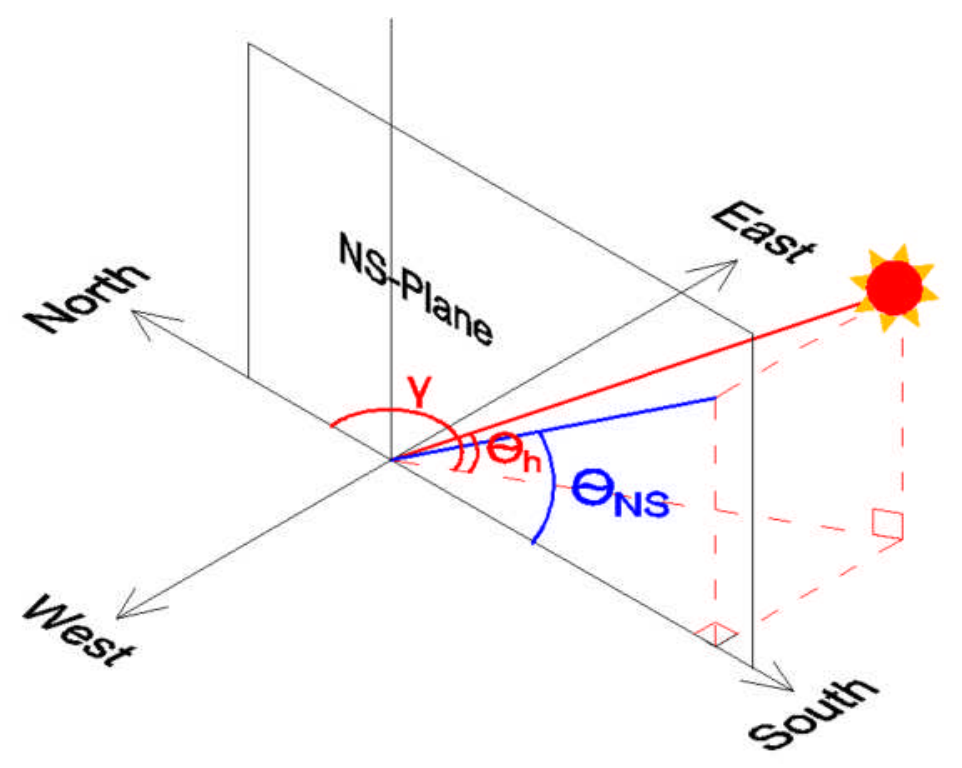

Fig. 1: Definition of south projection angle $\theta_{N S}$.

\subsection{Inner south projection angle}

As mentioned before, due to refraction on the air-dielectric interface, the sunlight path within a dielectric CPC would differ from a conventional CPC for the same sun position. Therefore, the south projection angle of the refracted light rather than that of the incident light would be useful in the performance analysis of dielectric CPC and it is named as "inner south projection angle" and denoted with $\theta_{N S}{ }^{\prime}$; accordingly, the south projection angle of the incident sunlight is named as "outer south projection angle" and its symbol is $\theta_{N S}$. Fig. 2 illustrates the outer and inner south projection angles on the transversal plane of an east-west orientated trough dielectric CPC, i.e., the meridional plane. According to the working principle of the dielectric CPC, for nonmeridional rays, whether the rays can reach the base of dielectric CPC is based on the 
comparison between the inner half acceptance angle and the north-south projected refraction angle which equals " $90^{\circ}$-tilt angle-inner south projection angle". The refracted rays will be concentrated on the base of dielectric CPC if the projected refraction angle is smaller than the inner half acceptance angle (light path $\mathbf{a}$ in Fig 2), otherwise the refracted lights will transmit through the profile of the dielectric CPC (light path $\boldsymbol{b}$ in Fig. 2). The inner half acceptance angle is related to the geometrical concentration ratio of dielectric CPC, while the projected refraction angle is related to the inner south projection angle and the tilt angle of an east-west orientated trough dielectric CPC.

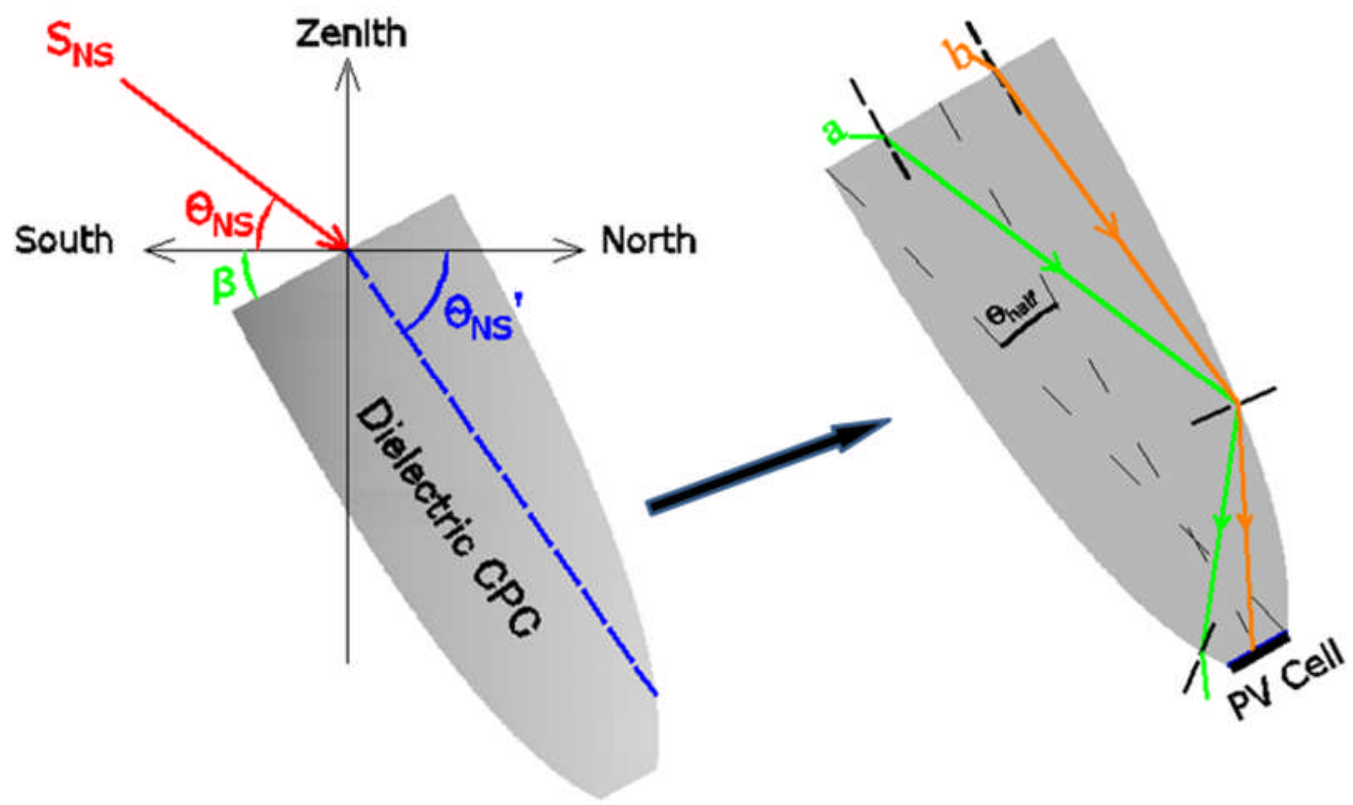

Fig. 2: Illustration of outer $\theta_{N S}$ and inner $\theta_{N S}$ south projection angle, respectively; $S_{N s:}$ projected solar position on SN Plane; $\beta$ : tilt angle of dielectric CPC; $\theta_{\text {half }}$ : inner half acceptance angle of dielectric CPC.

\section{Calculation and analysis of inner south projection angle}

\subsection{Calculation process}

In order to calculate the inner south projection angle, a mathematical coordinate system is employed and shown in Fig. 3, where the south, east and zenith directions are denoted with $\mathrm{x}, \mathrm{y}$ and $\mathrm{z}$ axis, respectively. The solar 
position vector is indicated with $S$, and its altitude and azimuth are $\theta_{h}$ and $\gamma$. The plane $A B C D$ stands for the interface between air and dielectric material, i.e., front aperture of dielectric CPC, which is tilted by $\beta$ to south from the horizontal plane. The line $N O N^{\prime}$ is normal to the plane $A B C D$, so it is tilted by $\beta$ to the $z$ axis. The line $S O$ stands for the incident light and $O S_{1}$ stands for the refracted light; the angle between the line $S O$ and the normal $N O N^{\prime}$ is the incidence angle $\theta_{i}$ and the angle between the line $O S_{1}$ and $N O N^{\prime}$ is the refraction angle $\theta_{i}{ }^{\prime}$. The line $O S_{1}{ }^{\prime}$ is the extension of the line $S_{1} O$, so the position of $S_{1}{ }^{\prime}$ could be regarded as the equivalent sun position for light path within the dielectric CPC. The line $S O$, the normal $N O N^{\prime}$ and the line $O S_{1}$ are on the plane of incidence (plane $\mathrm{SNS}_{1} \mathrm{~N}_{1}$ ). The relationship between the incidence angle $\theta_{i}$ and refraction angle $\theta_{i}{ }^{\prime}$ should meet the Snell's law:

$$
n=\frac{\sin \theta_{i}}{\sin \theta_{i}{ }^{\prime}}
$$

where $n$ is the refractive index.

Firstly, the length of the vector $\overrightarrow{S O}$ and $\overrightarrow{N O}$ may be set as 1 , then the positions of $S$ and $N$ can be defined as below, according to the geometry principle in Fig. 3:

$S:\left(-\cos \theta_{h} \cos \gamma, \cos \theta_{h} \sin \gamma, \sin \theta_{h}\right) ; N:(\sin \beta, 0, \cos \beta)$

The vector $\overrightarrow{S O}$ and $\overrightarrow{N O}$ are:

$\overrightarrow{S O}=\left(-\cos \theta_{h} \cos \gamma, \cos \theta_{h} \sin \gamma, \sin \theta_{h}\right) ; \overrightarrow{N O}=(\sin \beta, 0, \cos \beta)$

The incidence angle $\theta_{i}$, i.e., angle between $\overrightarrow{S O}$ and $\overrightarrow{N O}$, is:

$$
\cos \theta_{i}=\frac{\overrightarrow{S O} \cdot \overrightarrow{N O}}{|\overrightarrow{S O}| \cdot|\overrightarrow{N O}|}=-\cos \theta_{h} \cos \gamma \sin \beta+\sin \theta_{h} \cos \beta
$$




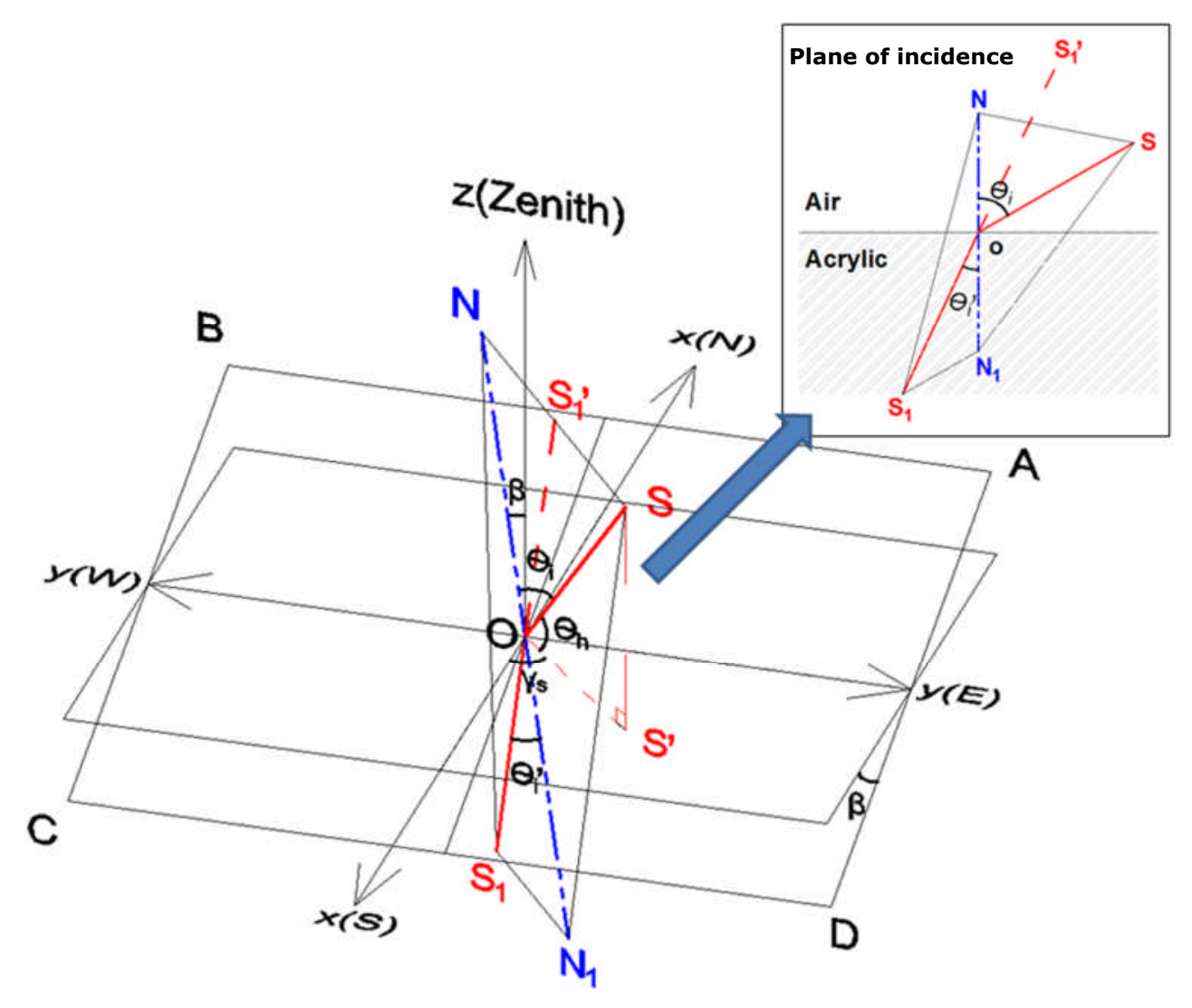

Fig. 3: Coordinate system for vector analysis of optical path. S: sun position; $S_{1}$ ': equivalent sun position; $\theta_{h}$ : solar altitude; $y$ : solar azimuth; $\theta_{i}$ incidence angle; $\theta_{i}$ ': refraction angle; $x$-axis: $N$-S direction; $y$-axis: $E-W$ direction; $z$-axis: zenith direction; SO: incident light; $O S_{1}$ : refracted light; NON'; normal of tilted surface.

According to the law of refraction, the $\overrightarrow{S O}$ and $\overrightarrow{N O}$ are on the same surface, i.e., plane of incidence, the surface normal vector $\vec{n}$ of the plane $\mathrm{SNS}_{1} \mathrm{~N}_{1}$ could be obtained:

$$
\begin{aligned}
\vec{n}=\overrightarrow{S O} \times \overrightarrow{N O} & =\left|\begin{array}{ccc}
i & j & k \\
-\cos \theta_{h} \cos \gamma & \cos \theta_{h} \sin \gamma & \sin \theta_{h} \\
\sin \beta & 0 & \cos \beta
\end{array}\right| \\
& =\left(\cos \theta_{h} \sin \gamma \cos \beta\right) i-\left(-\cos \theta_{h} \cos \gamma \cos \beta-\sin \theta_{h} \sin \beta\right) j \\
& +\left[-\cos \theta_{h} \sin \gamma \sin \beta\right] k
\end{aligned}
$$

Thus the surface equation of $\mathrm{SNS}_{1} \mathrm{~N}_{1}$ is

$x\left(\cos \theta_{h} \sin \gamma \cos \beta\right)-\mathrm{y}\left(-\cos \theta_{h} \cos \gamma \cos \beta-\sin \theta_{h} \sin \beta\right)-\mathrm{z}\left(\cos \theta_{h} \sin \gamma \sin \beta\right)=0$ 
Then assuming the position unit vector $\overrightarrow{S_{1}{ }^{\prime} O}=\left(x_{0}, y_{0}, z_{0}\right)$ and its length is 1 , thus the following two equations can be obtained:

The angle between $\overrightarrow{S_{1}{ }^{\prime} O}$ and $\overrightarrow{N O}$ equals to the angle between $\overrightarrow{O S_{1}}$ and $\overrightarrow{N O}$ (refraction angle) as the $O S_{1}{ }^{\prime}$ is the reversed extension line of $O S_{1}$, thus

$\cos \theta_{i}{ }^{\prime}=\frac{\overrightarrow{S_{1}{ }^{\prime} O} \cdot \overrightarrow{N O}}{\left|\overrightarrow{S_{1}{ }^{\prime} O}\right| \cdot|\overrightarrow{N O}|}=x_{0} \times \sin \beta+z_{0} \times \cos \beta$

Where refraction angle $\theta_{i}{ }^{\prime}$ could be obtained by the Snell's Law (Equation 2)

The angle between $\overrightarrow{S_{1}{ }^{\prime} O}$ and $\overrightarrow{S O}$ is $\Delta \theta_{i}$ :

$\cos \Delta \theta_{i}=\cos \left(\theta_{i}-\theta_{i}{ }^{\prime}\right)=\frac{\overrightarrow{S_{1}{ }^{\prime} O} \cdot \overrightarrow{S O}}{\left|\overrightarrow{S_{1}{ }^{\prime} O}\right| \cdot|\overrightarrow{S O}|}=x_{0}\left(-\cos \theta_{h} \cos \gamma\right)+y_{0}\left(\cos \theta_{h} \sin \gamma\right)+z_{0}\left(\sin \theta_{h}\right)$

As $S_{1}{ }^{\prime}$ is also located on the $\mathrm{SNS}_{1} \mathrm{~N}_{1}$ surface, thus it should meet the surface Equation 3; Therefore, the value for $x_{0}, y_{0}$ and $z_{0}$ could be obtained by solving Equation 4, 5 and 6.

As mentioned before, $S_{1}{ }^{\prime}$ could be regarded as the equivalent sun position for light path within the dielectric material and the length of $\overrightarrow{S_{1}{ }^{\prime} O}$ is 1 ; the position of $S_{1}{ }^{\prime}$ could be expressed by:

$S_{1}{ }^{\prime}:\left(-\cos \theta_{h}{ }^{\prime} \cos \gamma^{\prime}, \cos \theta_{h}{ }^{\prime} \sin \gamma^{\prime}, \sin \theta_{h}{ }^{\prime}\right)$

where $\theta_{h}{ }^{\prime}$ is the equivalent solar altitude; $\gamma^{\prime}$ is the equivalent solar azimuth. Therefore, there are:

$\left\{\begin{array}{c}x_{0}=-\cos \theta_{h}{ }^{\prime} \cos \gamma^{\prime} \\ y_{0}=\cos \theta_{h}{ }^{\prime} \sin \gamma^{\prime} \\ z_{0}=\sin \theta_{h}{ }^{\prime}\end{array}\right.$

According to the calculation of south projection angle in Equation 1, the south projection angle for the equivalent sun position, i.e. the inner south projection angle within a dielectric CPC can be calculated as: 
$\tan \theta_{N S}{ }^{\prime}=-\frac{\tan \theta_{h}{ }^{\prime}}{\cos \gamma^{\prime}}=\frac{z_{0}}{x_{0}}$

Where

$z_{0}=\frac{\left(\cos \theta_{h} \cos \gamma \cos \beta+\sin \theta_{h} \sin \beta\right)\left(\cos \Delta \theta_{i} \sin \beta+\cos \theta_{i}{ }^{\prime} \cos \theta_{h} \cos \gamma\right)+\left(\cos \theta_{h} \sin \gamma\right)^{2} \cos \beta \cos \theta_{i}{ }^{\prime}}{\left(\cos \theta_{h} \cos \gamma \cos \beta+\sin \theta_{h} \sin \beta\right)^{2}+\left(\cos \theta_{h} \sin \gamma\right)^{2}}$

$x_{0}=-\frac{\left(\cos \theta_{h} \cos \gamma \cos \beta+\sin \theta_{h} \sin \beta\right)\left(\cos \Delta \theta_{i} \cos \beta-\cos \theta_{i}{ }^{\prime} \sin \theta_{h}\right)-\left(\cos \theta_{h} \sin \gamma\right)^{2} \sin \beta \cos \theta_{i}{ }^{\prime}}{\left(\cos \theta_{h} \cos \gamma \cos \beta+\sin \theta_{h} \sin \beta\right)^{2}+\left(\cos \theta_{h} \sin \gamma\right)^{2}}$

Thus Equation 8 could be rewritten as:

$$
\left\{\begin{array}{c}
\tan \theta_{N S^{\prime}}=\frac{z_{0}}{x_{0}}=\frac{\left(\cos \theta_{h} \cos \gamma \cos \beta+\sin \theta_{h} \sin \beta\right)\left(\cos \Delta \theta_{i} \sin \beta+\cos \theta_{i}{ }^{\prime} \cos \theta_{h} \cos \gamma\right)+\left(\cos \theta_{h} \sin \gamma\right)^{2} \cos \beta \cos \theta_{i}{ }^{\prime}}{\left(\cos \theta_{h} \sin \gamma\right)^{2} \sin \beta \cos \theta_{i}{ }^{\prime}-\left(\cos \theta_{h} \cos \gamma \cos \beta+\sin \theta_{h} \sin \beta\right)\left(\cos \Delta \theta_{i} \cos \beta-\cos \theta_{i}{ }^{\prime} \sin \theta_{h}\right)} \\
\cos \theta_{i}{ }^{\prime}=\sqrt{1-\left(\frac{\sin \theta_{i}}{n}\right)^{2}}=\frac{\sqrt{n^{2}+\left(\sin \theta_{h} \cos \beta-\cos \theta_{h} \cos \gamma \sin \beta\right)^{2}-1}}{n} \\
\cos \Delta \theta_{i}=\cos \left(\theta_{i}-\theta_{i}{ }^{\prime}\right)=\cos \theta_{i} \times \cos \theta_{i}{ }^{\prime}+\sin \theta_{i} \times \sin \theta_{i}{ }^{\prime}
\end{array}\right.
$$

It could be found that the inner south projection angle is related to the solar position, tilt angle of dielectric CPC and the refractive index of dielectric material which determines the refraction angle.

\subsection{Example of calculation}

For example, in Nottingham, the sun position at 10 am $21^{\text {st }}$ June is $53.14^{\circ}$ of altitude $\left(\theta_{h}\right)$ and $131.81^{\circ}$ of azimuth $(\gamma)$, its corresponding projection angle on the north-south meridian plane is $63.44^{\circ}$ from Equation 1. The unit vector of the solar position is:

$\overrightarrow{S O}=\left(-\cos \theta_{h} \cos \gamma, \cos \theta_{h} \sin \gamma, \sin \theta_{h}\right)=(0.40,0.45,0.80)$

If a trough dielectric CPC is made of acrylic (with the refractive index of 1.5), being orientated east-west and tilted by $15^{\circ}$, the normal vector of the entrance surface of CPC is:

$\overrightarrow{N O}=(\sin \beta, 0, \cos \beta)=(0.26,0,0.26)$ 
From Equation 3, the cosine of incidence angle $\theta_{i}$ is:

$\cos \theta_{i}=-\cos \theta_{h} \cos \gamma \sin \beta+\sin \theta_{h} \cos \beta=0.876$

The incidence angle $\theta_{i}$ is then obtained:

$\theta_{i}=\cos ^{-1}\left(\cos \theta_{i}\right)=28.79^{\circ}$

From Equation 2, the refraction angle $\theta_{i}{ }^{\prime}$ is then given:

$\theta_{i}{ }^{\prime}=\sin ^{-1}\left(\sin \theta_{i}{ }^{\prime}\right)=\sin ^{-1}\left(\frac{\sin \theta_{i}}{n}\right)=18.73^{\circ}$

Therefore, the values of all the relevant angles in Equation 9 can be summarised in the following table:

Table 1: Relevant angles for example calculation of inner south projection angle in Equation 9.

\begin{tabular}{cccccc}
\hline $\begin{array}{c}\text { Solar } \\
\text { altitude } \theta_{h}\end{array}$ & $\begin{array}{c}\text { Solar } \\
\text { azimuth } \gamma\end{array}$ & $\begin{array}{c}\text { Tilt angle } \\
\text { of dielectric } \\
\text { CPC } \beta\end{array}$ & $\begin{array}{c}\text { Incidence } \\
\text { angle } \theta_{i}\end{array}$ & $\begin{array}{c}\text { Refracted } \\
\text { angle } \theta_{i}^{\prime}\end{array}$ & $\Delta \theta_{i}$ \\
\hline $53.14^{\circ}$ & $131.81^{\circ}$ & $15^{\circ}$ & $28.79^{\circ}$ & $18.73^{\circ}$ & $10.06^{\circ}$ \\
\hline
\end{tabular}

Substituting them into Equation 9 could give the corresponding inner south projection angle within the dielectric CPC:

$\tan \theta_{N S}{ }^{\prime}=2.54$

Thus inner south projection angle $\boldsymbol{\theta}_{\boldsymbol{N}}{ }^{\prime}=\mathbf{6 7 . 8}^{\circ}$ for an east-west orientated trough dielectric CPC made of acrylic $(n=1.5)$ and tilted 15

3.3 Comparison of outer and inner south projection angles and their adaptability to determine the optical performance of dielectric CPC

According to the definitions and calculation methods of both outer and inner south projection angles, the value of these two angles could be obtained if the 
solar position and the tilt angle of a dielectric CPC are given. In order to compare the difference of outer and inner south projection angles, the monthly variation of them are displayed in Fig. 4 \& 5 for the location of Nottingham (Latitude: $53^{\circ} \mathrm{N}$; Longitude: $1.2^{\circ} \mathrm{W}$ ). A non-truncated dielectric CPC-4.0 (refractive index $\mathrm{n}=1.5$ ) was considered, which has inner and outer half acceptance angle of $14.48^{\circ}$ and $22.02^{\circ}$. The dielectric CPC was east-west orientated with a tilt angle of $50^{\circ}$, which is normally a recommended tilt angle for solar receivers in Nottingham. To simplify the figure, the $21^{\text {st }}$ day of each month was chosen to represent its corresponding month. The upper and lower limit projection angles (90 - tilt angle \pm half acceptance angle) for the chosen dielectric CPC were also given.

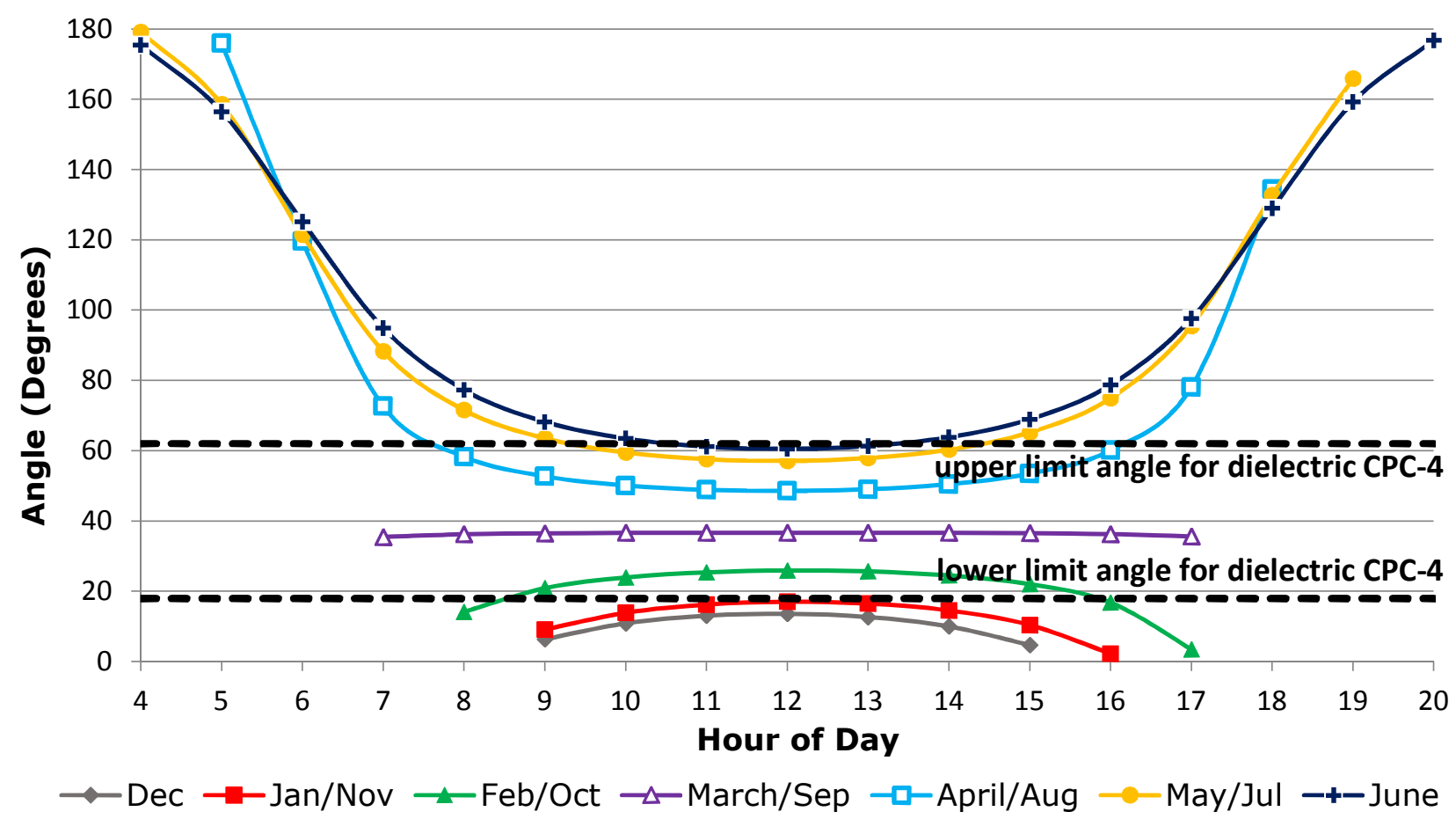

Fig. 4: Monthly outer south projection angle in Nottingham (21 ${ }^{\text {st }}$ day of each month). 


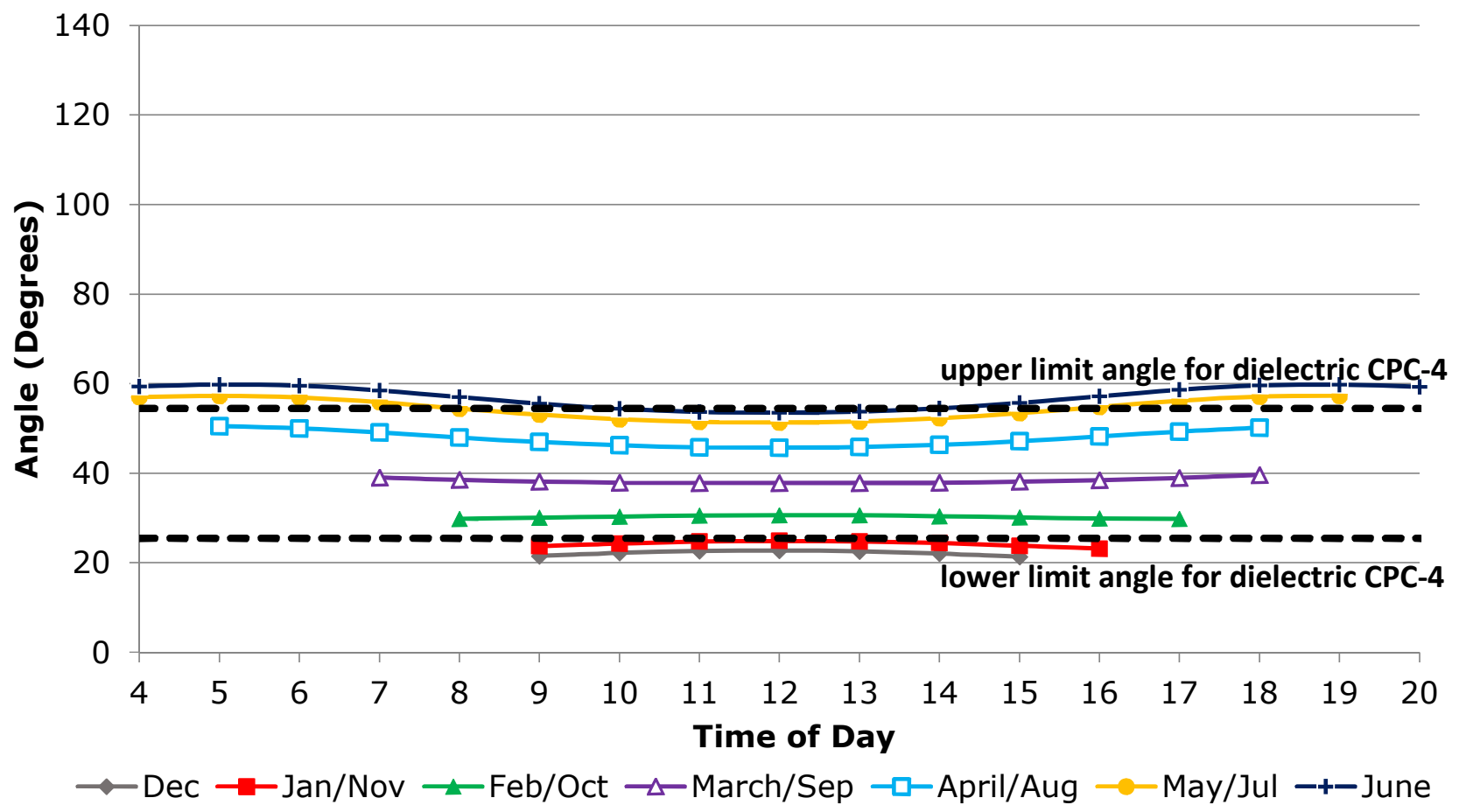

Fig. 5: Monthly inner south projection angle for the surface tilt angle $50^{\circ}$ in Nottingham (21 ${ }^{\text {st }}$ day of each month).

It could be observed from Figs. 4 and 5 that the annual variation of outer south projection angle is much larger the inner ones; and their daily variation patterns on the chosen days are also different. More importantly, the difference between the outer and inner south projection angles could also be observed when they are compared with the acceptance angle of dielectric CPC. For example, on $21^{\text {st }}$ April/August, the outer south projection angles before 7am and after $17 \mathrm{pm}$ are beyond the outer acceptance angle of dielectric CPC; while the inner south projection angles at the same time are within the inner acceptance angle of dielectric CPC, which means different results would be concluded on whether the solar radiation could be collected or transmitted through the dielectric CPC. Similar difference could also be found at time before $8 \mathrm{am}$ and after $16 \mathrm{pm}$ on $21^{\text {st }}$ February/October. In order to investigate which projection angle is more adoptable in determining the angular optical performance of dielectric CPC, the ray tracing simulation software Photopia (LtiOptics, 2013) was used. Photopia is a widely used 3D CAD based simulation software for complicated optical systems and has been validated in previous researches (Wittkopf et al., 2010). 
Photopia could also achieve daylighting simulation using the sky model that is based on the document IES-PR21 (Dutton and Shao, 2007).

Since a dielectric CPC may be used for combined application of daylighting and PV electricity generation (Yu et al., 2014a), the study of optical performance of dielectric CPC would be divided into two parts: the first one is optical efficiency, which is the ratio of received light on the base (onto which the solar cells are attached) of dielectric CPC to the incident light on the front aperture of dielectric $\mathrm{CPC}$, this value is related to the function of local electricity generation; on the other hand, the transmittance, which stands for the ratio of transmitted light through dielectric CPC to the incident light on the front aperture of dielectric CPC is used to indicate the daylighting control ability. The hourly optical performance of the studied dielectric CPC-4 on $21^{\text {st }}$ April and $21^{\text {st }}$ February were simulated and their results are shown in Figs. 6 and 7.

The simulation results in Figs. 6 and 7 reveal that no solar radiation could be transmitted through the studied dielectric CPC-4 on either $21^{\text {st }}$ April or $21^{\text {st }}$ February, and the solar radiation could be collected almost all the time in these two days, low optical efficiency would be found at $5-6 \mathrm{am}$ and $18 \mathrm{pm}$, this is mainly due to the incidence angle between sunlight and the normal of dielectric CPC front surface is close to $90^{\circ}$, such that sunlight would be mainly reflected by the CPC front surface. Additionally, the light path within the dielectric CPC on the east-west direction is much longer when the sun position is close to due east or west, therefore the optical absorption in the dielectric material could be considerable. The simulated optical performance therefore confirms that the inner south projection angle is more adoptable to be used as the parameter to determine the optical performance of trough dielectric CPC. The difference of inner and outer south projection angle in determining the optical performance of dielectric CPC would be further discussed in the next section. 


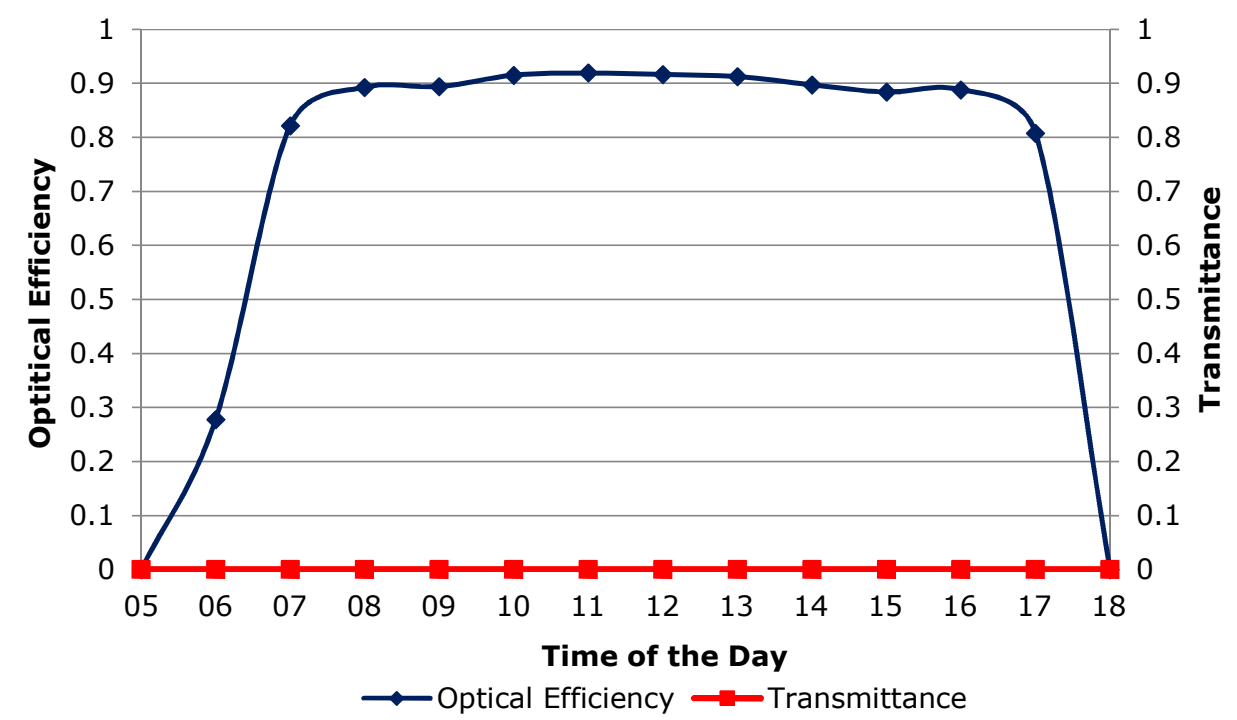

Fig. 6: Optical performance of dielectric CPC-4 (east-west orientated, $50^{\circ}$ tilt to south) in Nottingham on $21^{\text {st }}$ April.

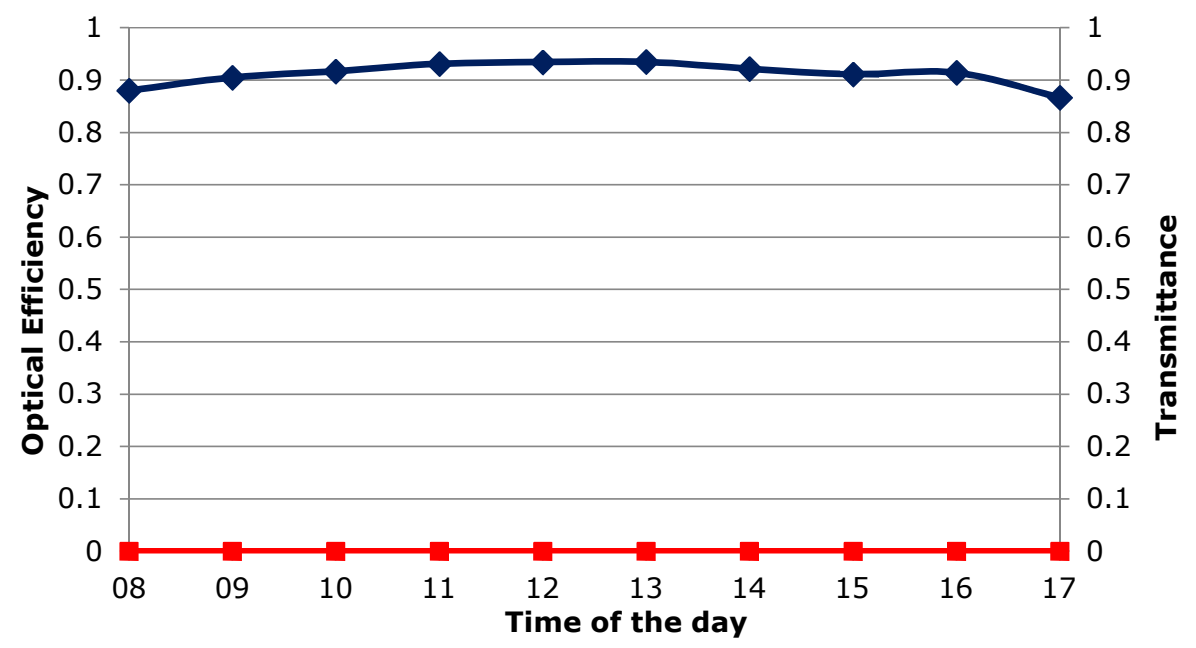

$\longrightarrow$ Optical Efficiency $\longrightarrow$ Transmittance

Fig. 7: Optical performance of dielectric CPC-4 (east-west orientated, $50^{\circ}$ tilt to south) in Nottingham on $21^{\text {st }}$ February.

\section{The correlation between inner and south projection angle and optical performance of dielectric CPC}

According to above observation, the optical performance of dielectric CPC should be more related to the inner south projection angle rather than the outer one. Therefore, the main aim of this section is to investigate the correlation between inner south projection angle and optical performance of dielectric CPC for various solar azimuth angles, and for the comparison purpose the 
correlation between outer south projection angle and optical performance of dielectric CPC is also investigated.

In this study, only the beam solar radiation is considered to investigate the angular performance of dielectric CPC, the optical efficiency and transmittance of a dielectric CPC for diffuse skylight is not quite related to south projection angle and could be approximately given from the geometrical concentration ratio (Rabl et al., 1980, Su et al., 2012a). The dimension and physical properties of selected dielectric CPC unit model and the setup for the simulation are the same as the one studied in the authors' previous research and summaried in Table 2 (Yu et al., 2014a). The ray-tracing software Photopia was employed to evaluate a truncated dielectric CPC from a full height CPC of 4.0 geometric concentration ratio, and the indicative parameters of optical efficiency and transmittance were used.

\section{Table 2: dimension and physical properties of truncated dielectric CPC}

\section{Dimension or Physical Properties}

Dimension

\section{Value}

Front aperture width: $18 \mathrm{~mm}$;

Base aperture width: $5 \mathrm{~mm}$

Height: $24.2 \mathrm{~mm}$

Trough length: $96 \mathrm{~mm}$
Geometric Concentration Ratio

Inner/Outer Half Acceptance Angle

Refractive Index of Dielectric Material

Extinction Coefficient of Dielectric Material

Orientation
3.6

$14.47^{\circ} / 22.02^{\circ}$

1.5

$2.525 \mathrm{~m}^{-1}$

longitudinal axis in the east-west direction, $0^{\circ}$ tilted angle to south.

4.1 The correlation between inner south projection angle and optical efficiency 
The result in Fig. 8 clearly reveals the angular change of dielectric CPC's optical efficiency: two critical angles of about $75^{\circ}$ and $105^{\circ}$ could be observed and their gap (about $30^{\circ}$ ) agrees with the inner acceptance angle of studied dielectric CPC. The angle ranges of about $65^{\circ}$ to $75^{\circ}$ and $105^{\circ}$ to $115^{\circ}$ are due to truncation from a full height CPC. Additionally, the angular optical efficiency of the dielectric CPC at each solar azimuth angle almost overlaps apart from some extreme solar azimuth angles; which indicates that the inner south projection angle seems to be the only factor influencing the optical efficiency of dielectric CPC. For some extreme solar azimuth angles which are between $75^{\circ}$ and $105^{\circ}$, it means that the sun position is very close to east or west, the light path within dielectric CPC would be longer than ones under other solar azimuth angles, the influence of optical absorption within the dielectric material might be large. Therefore, the optical efficiency within this range is smaller under the same inner south projection angle. On the other hand, as shown in Fig. 9, the angular optical efficiency in terms of outer south projection angle did not show unique features under different solar azimuth angles, proofing that the outer south projection angle is not suitable for determining the angular change of dielectric CPC's optical efficiency.

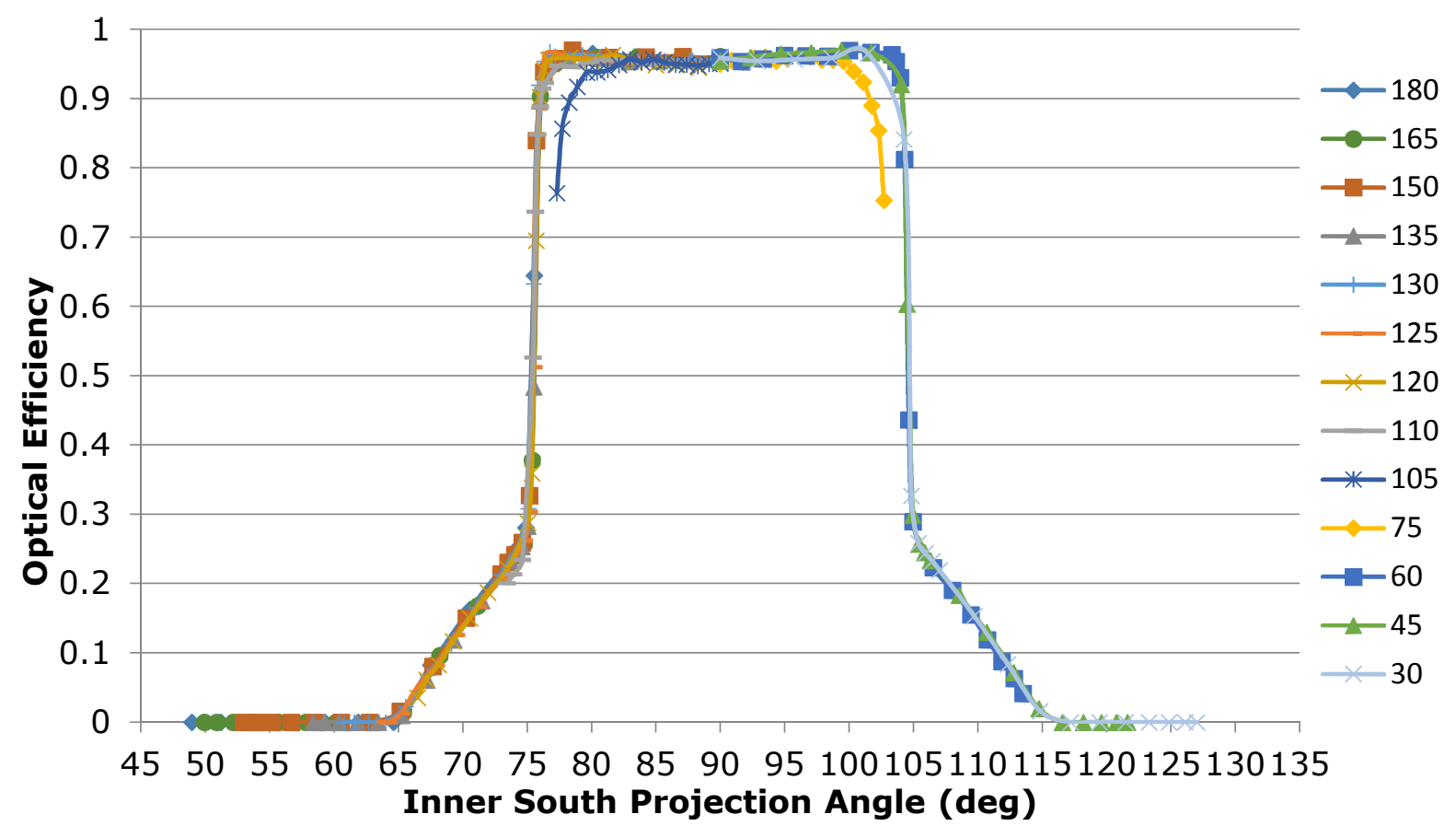

Fig. 8: The correlation between inner south projection angle and optical efficiency for various solar azimuth angles. 


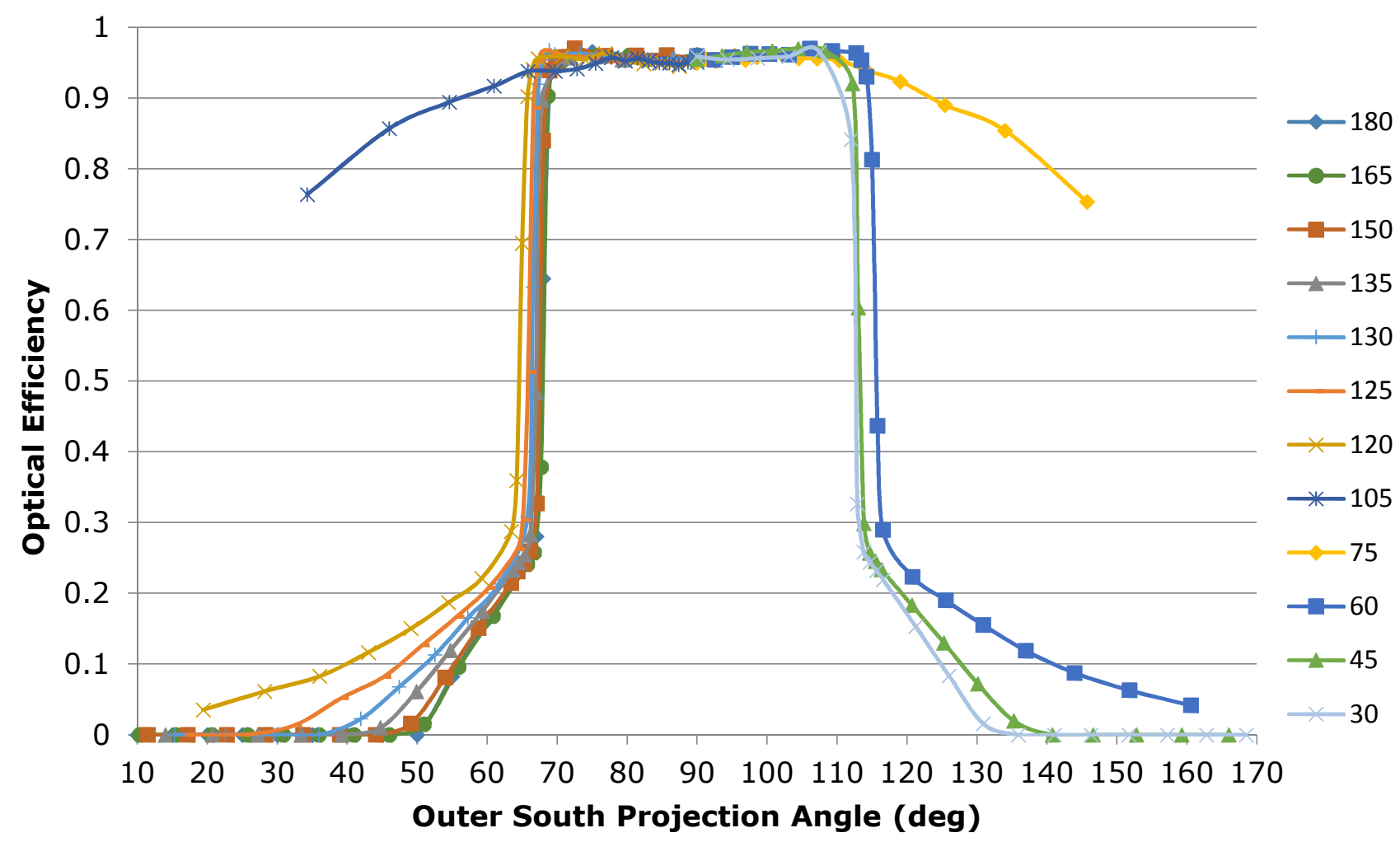

Fig. 9: The correlation between outer south projection angle and optical efficiency for various solar azimuth angles.

4.2 The correlation between inner south projection angle and transmittance

In the same way, the correlation between inner south projection angle and transmittance is also simulated and the results are presented in Fig. 10. Likewise the optical efficiency, two critical angles of $75^{\circ}$ and $105^{\circ}$ are clear shown for all solar azimuth angles, light could be transmitted only when the inner south projection angle is smaller or larger than critical angles. This feature is unique for a dielectric CPC. However, under the condition that the inner south projection angle is beyond the two critical angles, i.e. inner acceptance angle, the light transmittance seems to be diverse under different solar azimuth angles. This may be due to surface reflection as discussed below. 


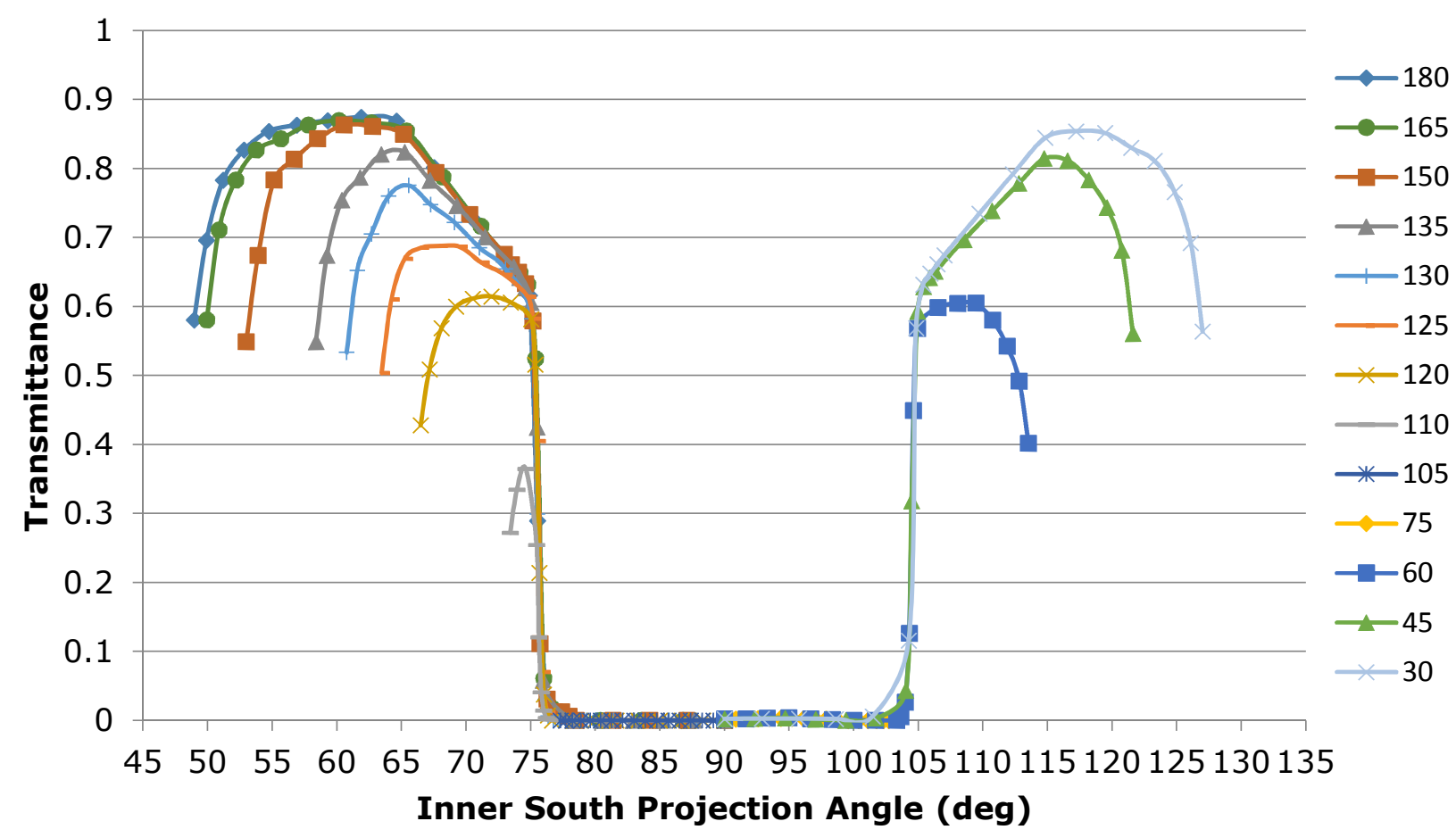

Fig. 10: The correlation between inner south projection angle and light transmittance for various solar azimuth angles.

On the interface of two mediums with different refractive indices, both the refraction and the reflection could occur. The fraction of the reflected lights could be described by Fresnel's Equations (Goldstein and Goldstein, 2011)

$R_{S}=\left|\frac{n_{1} \cos \theta_{i}-n_{2} \cos \theta_{i}{ }^{\prime}}{n_{1} \cos \theta_{i}+n_{2} \cos \theta_{i}{ }^{\prime}}\right|^{2}$
$R_{p}=\left|\frac{n_{1} \cos \theta_{i}{ }^{\prime}-n_{2} \cos \theta_{i}}{n_{1} \cos \theta_{i}{ }^{\prime}+n_{2} \cos \theta_{i}}\right|^{2}$

where $n_{1}$ and $n_{2}$ is the refractive indices of the two medium; $\theta_{i}$ is the incidence angle; $\theta_{i}{ }^{\prime}$ is the refraction angle; $R_{s}$ stands for the reflectance for s-polarized light; $R_{p}$ stands for the reflectance for $\mathrm{p}$-polarized light.

In this study, the light travels from the air to the dielectric material with refractive index of 1.5 , thus $n_{1}$ is 1 and $n_{2}$ is 1.5; the refraction angle can be calculated using the Snell's Law (Equation 2); the incident light is regarded as unpolarised (containing an equal mix of $s$ - and p-polarisations). Thus the total 
fraction of reflection on the air-dielectric interface could be calculated using Equation 12 and the relationship between the incidence angle and the fraction of reflection is summarised in Fig. 11.

$R=\frac{R_{s}+R_{p}}{2}=\frac{\left|\frac{n_{1} \cos \theta_{i}-n_{2} \cos \theta_{i}{ }^{\prime}}{n_{1} \cos \theta_{i}+n_{2} \cos \theta_{i}{ }^{\prime}}\right|^{2}+\left|\frac{n_{1} \cos \theta_{i}{ }^{\prime}-n_{2} \cos \theta_{i}}{n_{1} \cos \theta_{i}{ }^{\prime}+n_{2} \cos \theta_{i}}\right|^{2}}{2}$

After considering the surface reflection on the air-dielectric interface of dielectric CPC, a new figure is drawn to show the correlation between the inner south projection angle and the sum of light transmittance and surface reflection. The results shown in Fig. 12 are quite attractive, the line for each solar azimuth angle almost overlapped. Although they are not perfectly overlapped as the optical efficiency illustrated in Fig. 10, this result is still useful for the approximate prediction of light transmittance under certain inner south projection angle regardless of solar azimuth angle. The detailed prediction process for light transmittance and optical efficiency of tilted trough dielectric CPC would be presented in next section. Similarly, no unique correlation could be found between the outer south projection angle and the sum of light transmittance and surface reflection for various solar azimuth angles as it is presented in Fig. 13.

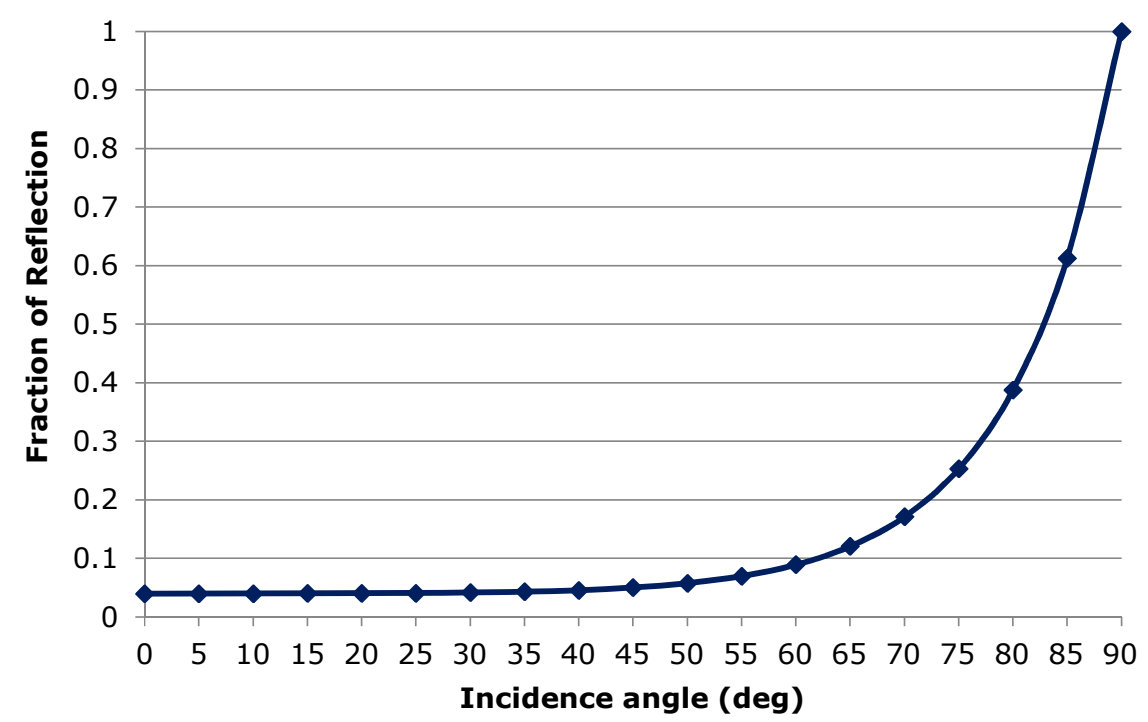

Fig. 11: Correlation between the incidence angle and fraction of surface reflection for unpolarised light travel from air $(n=1)$ to acrylic $(n=1.5)$. 


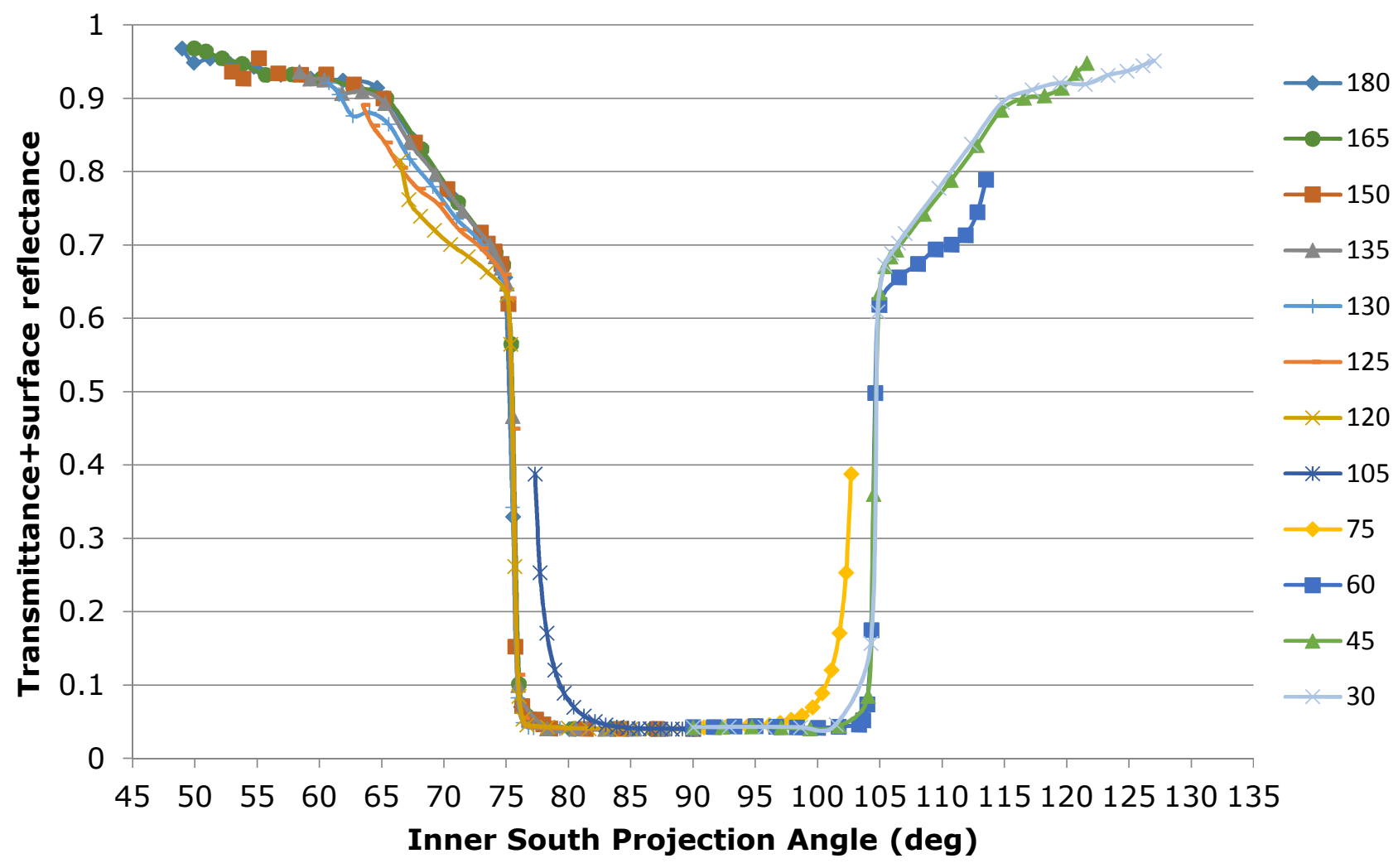

Fig. 12: The correlation between inner south projection angle and the sum of light transmittance and surface reflection for various solar azimuth angles.

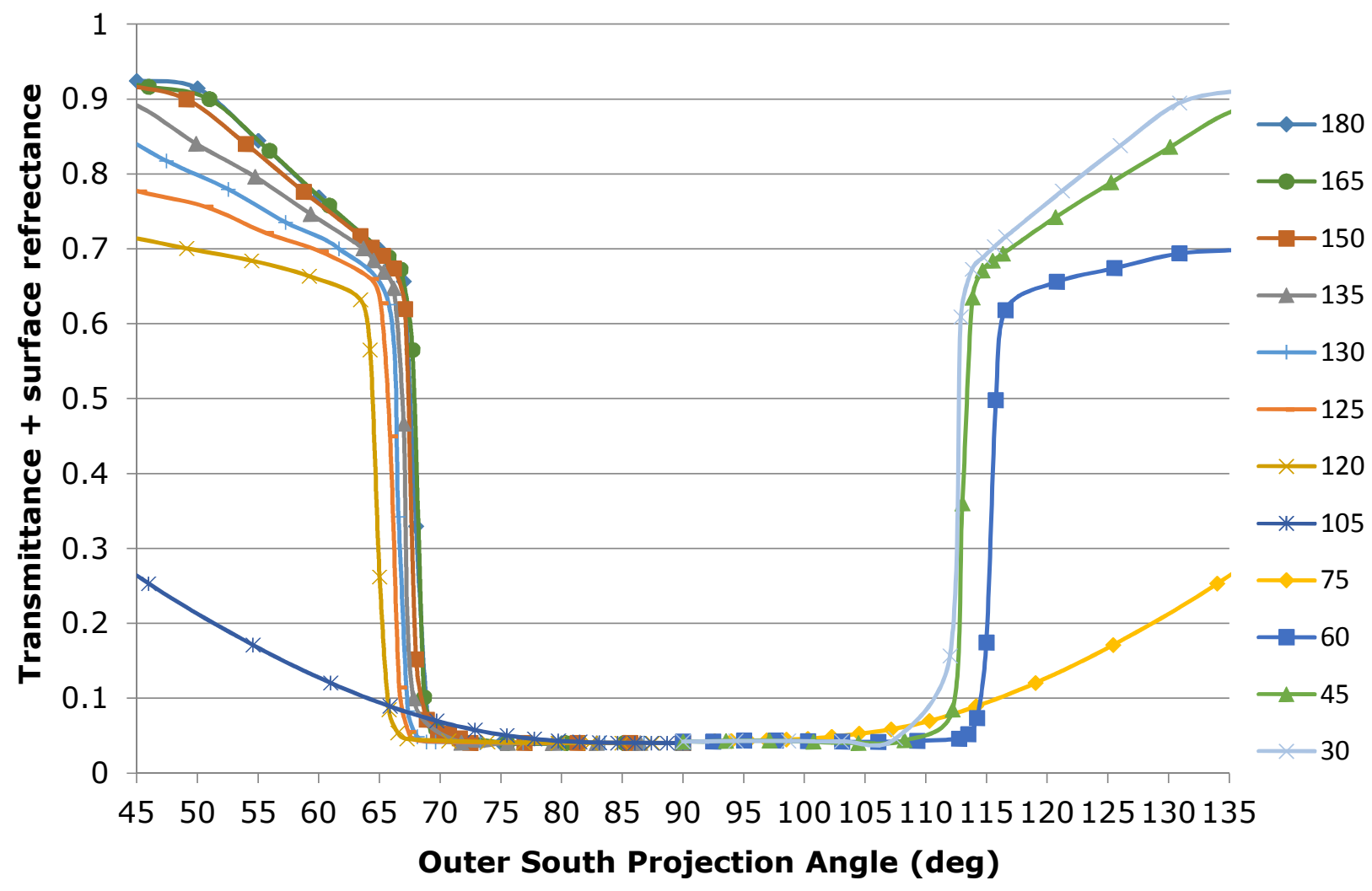

Fig. 13: The correlation between outer south projection angle and the sum of light transmittance and surface reflection for various solar azimuth angles. 


\section{Prediction of Transmittance and Optical Efficiency of dielectric CPC and its Verification}

In order to estimate the optical performance of dielectric CPC, it might be more accurate by using simulation software such as Photopia, but the correlation between inner south projection angle and angular optical performance of EWorientated trough dielectric CPC may provide a faster and informative way to predict its optical performance over a long period with changing sun position. In this section, a process of predicting the optical performance would be presented using some example solar positions, and then verification by Photopia simulation would be taken to verify the feasibility of the prediction method.

The example in Section 3.2 would be used again to shown the prediction process.

Step 1: determine the solar position:

The solar position can be calculated when the time and date are given for a location. For example, according to the Daylighting Calculation in Photopia, the sun position at $10 \mathrm{am}$ on $21^{\text {st }}$ June for Nottingham is $53.14^{\circ}$ of altitude and $131.81^{\circ}$ of azimuth.

Step 2: calculate the inner south projection angle:

The inner south projection angle within a trough dielectric CPC could be calculated using Equation 9. For a $15^{\circ}$ tilted dielectric CPC with refractive index of 1.5 , the inner south projection is $67.8^{\circ}$. The calculation process is described in Section 3.2.

Step 3: calculate the amount surface reflection:

The angle between the incident light and the normal of the tilted surface can be calculated using Equation 3: where $\theta_{h}$ is $53.14^{\circ} ; \gamma$ is $131.81^{\circ} ; \beta$ is $15^{\circ}$;

$$
\cos \theta_{i}=\cos 53.14 \times \cos (180-131.81) \times \sin 15+\sin 53.14 \times \cos 15=0.87 \rightarrow \theta_{i}=28.79^{\circ}
$$


Therefore, the incidence angle is $28.79^{\circ}$ and the corresponding surface reflection on the front aperture of dielectric CPC is about $4.13 \%$. According to the analysis presented in Section 4.2, the amount of surface reflection needs to be deducted when estimating the transmittance. Another purpose to calculate the incidence angle is that if $\theta_{i}$ is larger than $90^{\circ}$, there will be no light incident on the front surface of dielectric CPC, therefore both optical efficiency and transmittance should be $0 \%$, such as the case at $5 \mathrm{am}$ and $18 \mathrm{pm}$ on $21^{\text {st }}$ April in Nottingham for $50^{\circ}$ tilted dielectric CPC (Section 3.3).

Step 4: determine optical performance of tilted dielectric CPC

The Figs. 8 and 12 are based on the dielectric CPC whose tilt angle is $0^{\circ}$, while for the example given here, the tilt angle of the dielectric CPC is $15^{\circ}$, thus the horizontal axis of both Fig. 8 and 12 need to be move forward $15^{\circ}$ to get a new correlation between the inner south projection angle and optical performance. As a result, the critical inner south projection angles for the tilted dielectric CPC is $60^{\circ}$ and $90^{\circ}$. Since the calculated inner south projection angle for the given example is $67.8^{\circ}$, which is within the critical angles, the estimated optical efficiency is about $95 \%$ and the transmittance is about $0 \%$.

Take another date and time for example: $14: 00 \mathrm{pm}$ on $21^{\text {st }}$ December, Nottingham. The sun position is $8.73^{\circ}$ for altitude and $29.34^{\circ}$ for azimuth; the trough dielectric CPC is tilted $30^{\circ}$. The induced inner south projection angle is $31.83^{\circ}$. The incidence angle on the front surface of dielectric CPC is $55.79^{\circ}$ and the corresponding reflection fraction is $7.2 \%$. The horizontal axis of Figs. 8 and 12 needs to be move forward about $30^{\circ}$. Therefore the estimated optical efficiency is $0 \%$ and the transmittance is $92 \%-7.2 \%=84.8 \%$.

The above two cases were also simulated in Photopia, for the first case, the simulated result is $95.51 \%$ for the optical efficiency and $0 \%$ for transmittance. And for the second case, the simulated optical efficiency is $0 \%$ and transmittance is $83.17 \%$. Both simulation results of the above two cases are very close to the estimated ones. 
In order to further verify the prediction process, more groups of representative dates and tilted angles in Nottingham were chosen and used for comparison, and the results are listed in Table 2. It should be mentioned that the comparison results for only half day on the chosen dates are presented as the solar position is almost symmetrical to the midday. Fig. 14 is also given to provide a direct view of results comparison between simulated and estimated optical performance. The results shows that the most of the points are located around the line $y=x$, showing that the estimated results using the presented method are close to the simulation results from Photopia for the selected solar positions and tilt angles. It could also be found that the difference between the simulated and estimated results tends to be smaller when the sun position moves towards due south (midday), and the solar radiation around midday is the main interests of the solar energy application. Meanwhile, relatively large deviation could be found at 6am on $21^{\text {st }}$ June when the dielectric CPC is tilted $15^{\circ}$, which could be explained by the influence of considerable optical absorption in the dielectric material due to longer optical path when the sun position is close to the east. In general, it could be concluded that using the inner south projection angle to predict the optical performance of dielectric CPC seems to be an applicable method, which would provide convenience in analysing the annual performance of a dielectric CPC.

Table 3: Comparison of estimated and simulated results for optical performance of dielectric CPC under various conditions.

\begin{tabular}{|c|c|c|c|c|c|c|c|c|}
\hline & \multirow{2}{*}{$\begin{array}{l}\text { Local } \\
\text { Time }\end{array}$} & \multirow{2}{*}{$\theta_{h}, Y$} & \multirow{2}{*}{$\beta$} & \multirow{2}{*}{$\Theta_{N S^{\prime}}$} & \multicolumn{2}{|c|}{ Optical Efficiency } & \multicolumn{2}{|c|}{ Transmittance } \\
\hline & & & & & Estimated & Simulated & Estimated & Simulated \\
\hline \multirow{4}{*}{$\begin{array}{l}\frac{5}{0} \\
\frac{0}{\pi} \\
\frac{\pi}{2} \\
\vec{n} \\
\vec{n}\end{array}$} & 7am & $\begin{array}{l}8.24^{\circ} \\
101.76^{\circ}\end{array}$ & \multirow{4}{*}{$15^{\circ}$} & $67.08^{\circ}$ & $95 \%$ & $88.57 \%$ & $0 \%$ & $0 \%$ \\
\hline & 9am & $\begin{array}{l}24.54^{\circ} \\
128.16^{\circ}\end{array}$ & & $55.72^{\circ}$ & $13 \%$ & $15.63 \%$ & $67 \%$ & $62.50 \%$ \\
\hline & $11 \mathrm{am}$ & $\begin{array}{l}35.05^{\circ} \\
160.74^{\circ}\end{array}$ & & $51.10^{\circ}$ & $3 \%$ & $3.73 \%$ & $83 \%$ & $80.60 \%$ \\
\hline & $12 \mathrm{pm}$ & $\begin{array}{l}36.63^{\circ} \\
179.16^{\circ}\end{array}$ & & $50.56^{\circ}$ & $2 \%$ & $2.14 \%$ & $85 \%$ & $85.00 \%$ \\
\hline
\end{tabular}




\begin{tabular}{|c|c|c|c|c|c|c|c|c|}
\hline \multirow{4}{*}{ 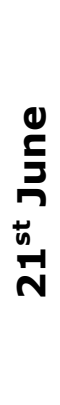 } & $6 a m$ & $\begin{array}{l}19.00^{\circ}, \\
75980^{\circ}\end{array}$ & \multirow{4}{*}{$15^{\circ}$} & $87.30^{\circ}$ & $50 \%$ & $24.44 \%$ & $17 \%$ & $26.67 \%$ \\
\hline & $8 a m$ & $\begin{array}{l}36.93^{\circ} \\
99.77^{\circ}\end{array}$ & & $76.10^{\circ}$ & $95 \%$ & $93.64 \%$ & $0 \%$ & $0 \%$ \\
\hline & $10 a m$ & $\begin{array}{l}53.14^{\circ} \\
131.80^{\circ}\end{array}$ & & $67.81^{\circ}$ & $95 \%$ & $95.51 \%$ & $0 \%$ & $0 \%$ \\
\hline & $12 \mathrm{pm}$ & $\begin{array}{l}60.47^{\circ} \\
178.46^{\circ}\end{array}$ & & $65.38^{\circ}$ & $95 \%$ & $95.40 \%$ & $0 \%$ & $0 \%$ \\
\hline \multirow{4}{*}{ 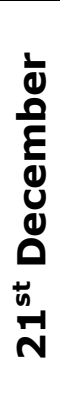 } & $9 a m$ & $\begin{array}{l}4.91^{\circ} \\
140.9^{\circ}\end{array}$ & \multirow{4}{*}{$15^{\circ}$} & $42.83^{\circ}$ & $0 \%$ & $0 \%$ & $70.5 \%$ & $70.00 \%$ \\
\hline & $10 a m$ & $\begin{array}{l}9.77^{\circ} \\
153.5^{\circ}\end{array}$ & & $40.60^{\circ}$ & $0 \%$ & $0 \%$ & $79.4 \%$ & $81.16 \%$ \\
\hline & $11 \mathrm{am}$ & $\begin{array}{l}12.74^{\circ} \\
167.65^{\circ}\end{array}$ & & $39.47^{\circ}$ & $0 \%$ & $0 \%$ & $83 \%$ & $82.93 \%$ \\
\hline & $12 \mathrm{pm}$ & $\begin{array}{l}13.58^{\circ} \\
178.25^{\circ}\end{array}$ & & $39.18^{\circ}$ & $0 \%$ & $0 \%$ & $84.4 \%$ & $84.7 \%$ \\
\hline \multirow{4}{*}{ 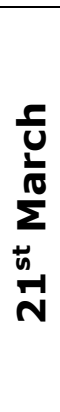 } & $7 a m$ & $\begin{array}{c}8.24^{\circ} \\
101.76^{\circ}\end{array}$ & \multirow{4}{*}{$30^{\circ}$} & $54.84^{\circ}$ & $95 \%$ & $94.20 \%$ & $0 \%$ & $0 \%$ \\
\hline & 9am & $\begin{array}{l}24.54^{\circ} \\
128.16^{\circ}\end{array}$ & & $47.78^{\circ}$ & $94 \%$ & $93.91 \%$ & $0 \%$ & $0 \%$ \\
\hline & $11 \mathrm{am}$ & $\begin{array}{l}35.05^{\circ} \\
160.74^{\circ}\end{array}$ & & $44.99^{\circ}$ & $25 \%$ & $28.66 \%$ & $56.9 \%$ & $59.87 \%$ \\
\hline & $12 \mathrm{pm}$ & $\begin{array}{l}36.63^{\circ} \\
179.16^{\circ}\end{array}$ & & $44.67^{\circ}$ & $25 \%$ & $26.22 \%$ & $57 \%$ & $62.81 \%$ \\
\hline \multirow{4}{*}{ 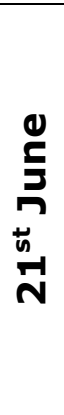 } & $6 a m$ & $\begin{array}{c}19.00^{\circ} \\
76^{\circ}\end{array}$ & \multirow{4}{*}{$30^{\circ}$} & $77.72^{\circ}$ & $22 \%$ & $13.79 \%$ & $24.5 \%$ & $20.69 \%$ \\
\hline & $8 a m$ & $\begin{array}{l}36.93^{\circ}, \\
99.77^{\circ}\end{array}$ & & $68.24^{\circ}$ & $95 \%$ & $93.33 \%$ & $0 \%$ & $0 \%$ \\
\hline & $10 a m$ & $\begin{array}{l}53.14^{\circ} \\
131.80^{\circ}\end{array}$ & & $62.15^{\circ}$ & $95 \%$ & $95.60 \%$ & $0 \%$ & $0 \%$ \\
\hline & $12 \mathrm{pm}$ & $\begin{array}{l}60.47^{\circ} \\
178.46^{\circ}\end{array}$ & & $60.32^{\circ}$ & $95 \%$ & $96.07 \%$ & $0 \%$ & $0 \%$ \\
\hline \multirow{4}{*}{ 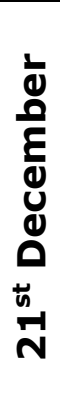 } & $9 a m$ & $\begin{array}{c}4.91^{\circ}, \\
140.97^{\circ}\end{array}$ & \multirow{4}{*}{$30^{\circ}$} & $32.58^{\circ}$ & $0 \%$ & $0 \%$ & $81.7 \%$ & $80.49 \%$ \\
\hline & $10 a m$ & $\begin{array}{c}9.77^{\circ}, \\
153.95^{\circ}\end{array}$ & & $31.65^{\circ}$ & $0 \%$ & $0 \%$ & $86.4 \%$ & $84.76 \%$ \\
\hline & $11 \mathrm{am}$ & $\begin{array}{l}12.74^{\circ} \\
167.65^{\circ}\end{array}$ & & $31.23^{\circ}$ & $0 \%$ & $0 \%$ & $87.6 \%$ & $86.56 \%$ \\
\hline & $12 \mathrm{pm}$ & $\begin{array}{l}13.58^{\circ} \\
178.25^{\circ} \\
\end{array}$ & & $31.13^{\circ}$ & $0 \%$ & $0 \%$ & $87.8 \%$ & $87.10 \%$ \\
\hline \multirow{4}{*}{ 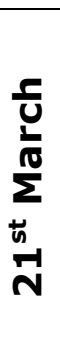 } & $7 a m$ & $\begin{array}{c}8.24^{\circ}, \\
101.76^{\circ}\end{array}$ & \multirow{4}{*}{$50^{\circ}$} & $39.01^{\circ}$ & $95 \%$ & $93.62 \%$ & $0 \%$ & $0 \%$ \\
\hline & 9am & $\begin{array}{l}24.54^{\circ} \\
128.16^{\circ}\end{array}$ & & $38.12^{\circ}$ & $95 \%$ & $92.74 \%$ & $0 \%$ & $0 \%$ \\
\hline & $11 \mathrm{am}$ & $\begin{array}{l}35.05^{\circ} \\
160.74^{\circ}\end{array}$ & & $37.79^{\circ}$ & $95 \%$ & $91.95 \%$ & $0 \%$ & $0 \%$ \\
\hline & $12 \mathrm{pm}$ & $36.63^{\circ}$ & & $37.75^{\circ}$ & $95 \%$ & $95.55 \%$ & $0 \%$ & $0 \%$ \\
\hline
\end{tabular}




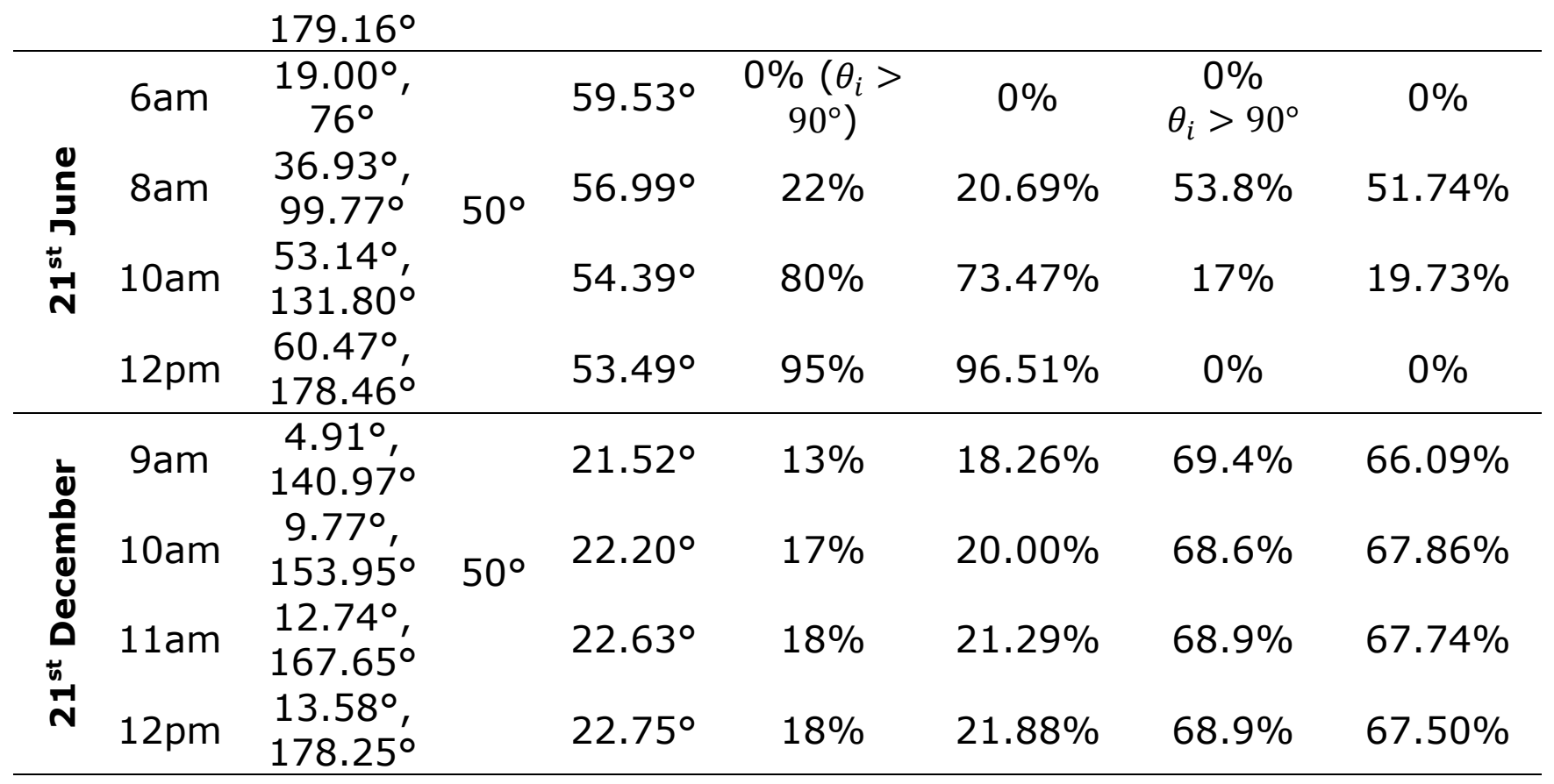

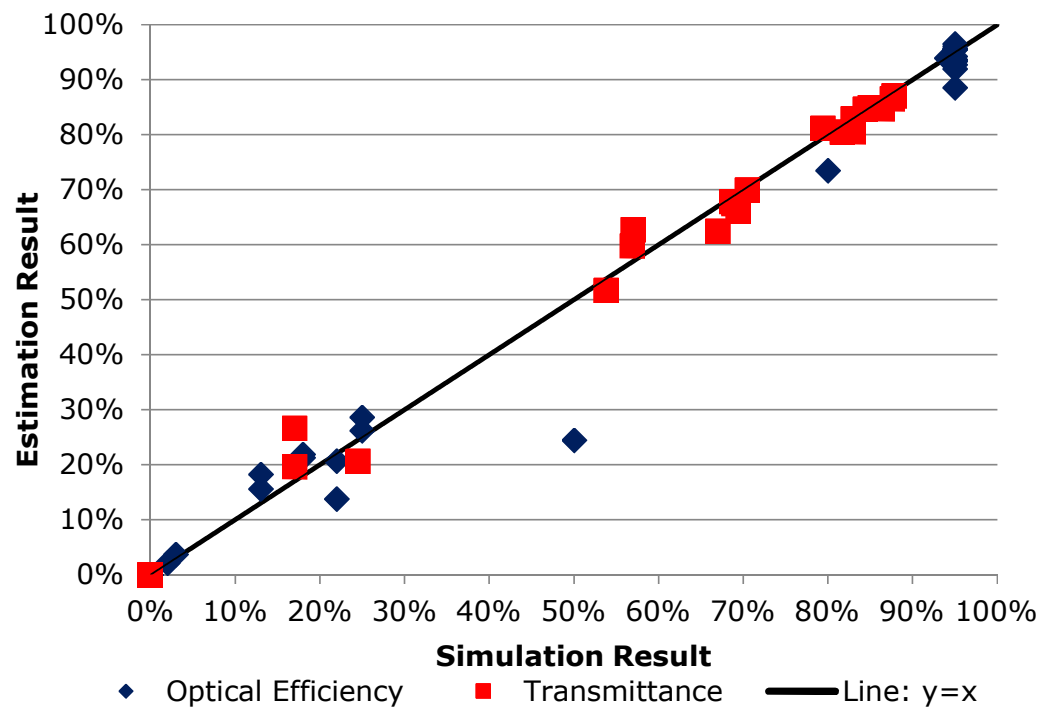

Fig. 14: Comparison of optical performance of dielectric CPC from simulation and estimation.

\section{Conclusions}

This paper has introduced the concept of inner south projection angle taking refraction into consideration. Different from the conventional definition or called outer south projection angle, it has been found that the inner south projection angle is related not only to the solar altitude and azimuth, but also the tilt angle 
and the refractive index of the dielectric CPC. The formula of the inner south projection angle has been derived using vector analysis. The monthly variation of the inner and outer south projection angles throughout a whole year in Nottingham is indicated by calculating the hourly values on the $21^{\text {st }}$ day of each month; the results show that the inner south projection angle is a more suitable indicator to determine whether the solar radiation could be collected or transmitted through a dielectric CPC.

Additionally, the correlation between the optical performance of dielectric CPC and the inner south projection at different solar azimuth angles is also obtained on the basis of Photopia simulation. The optical efficiency and transmittance are used to indicate the ability of a dielectric CPC for PV and daylighting application. The results show that there is a strong correlation between the optical efficiency of dielectric CPC and its inner south projection angle regardless of the solar azimuth angle; similar correlation could also be found for the transmittance if the surface reflection on the front aperture of dielectric CPC is considered. The above findings are quite attractive and provide convenience for predicting the optical efficiency and transmittance of dielectric CPC for annual performance analysis. The process of such prediction is illustrated using some examples and their results are verified by the Photopia simulation, indicating that such estimation method may be valid for both optical efficiency and transmittance.

According to the findings of this paper, some general rules in determining the optical performance of EW-orientated dielectric CPC could be concluded:

1) Determine the angular performance of dielectric CPC in terms of optical efficiency and transmittance by experiment or simulation tool such as Photopia.

2) Calculate the inner south projection angle according to the sun positon, material refractive index and tilt angle.

3) Estimate the optical performance at each sun position using the method provided. 
4) Optimise the concentration ratio (inner acceptance angle) and tilt angle according to the local climate characteristics to achieve the required daylight control and solar energy concentration.

Meanwhile, it should be mentioned that such prediction is for direct sunlight only. For the diffuse skylight, the optical efficiency and transmittance of a dielectric CPC is not quite related to certain angle and could be approximately given from the geometrical concentration ratio (Su et al., 2012a, Rabl et al., 1980).

\section{Acknowledgement}

The authors would like to thank the European Commission for a Marie Curie Fellowship grant (PIIF-GA-2010-275038).

\section{REFERENCE}

DUTTON, S. \& SHAO, L. 2007. Raytracing simulation for predicting light pipe transmittance. International Journal of Low-Carbon Technologies, 2, 339358.

GOLDSTEIN, D. \& GOLDSTEIN, D. H. 2011. Polarized Light, Revised and Expanded, Taylor \& Francis.

GORDON, J. M., LASKEN, M. \& RIES, H. 1996. Upper bounds for the yearly energy delivery of stationary solar concentrators and the implications for concentrator optical design. Solar Energy, 58, 197-202.

LI, G., SU, Y., PEI, G., ZHOU, H., YU, X., JI, J. \& RIFFAT, S. 2013. An Outdoor Experiment of a Lens-Walled Compound Parabolic Concentrator Photovoltaic Module on a Sunny Day in Nottingham. Journal of Solar Energy Engineering, 136, 021011-021011.

LTIOPTICS. 2013. Available: http://www.Itioptics.com/Photopia/overview.html [Accessed, May 2014].

MALLICK, T. K. \& EAMES, P. C. 2007. Design and fabrication of low concentrating second generation PRIDE concentrator. Solar Energy Materials and Solar Cells, 91, 597-608.

MALLICK, T. K., EAMES, P. C. \& NORTON, B. 2006. Non-concentrating and asymmetric compound parabolic concentrating building façade integrated photovoltaics: An experimental comparison. Solar Energy, 80, 834-849.

PEI, G., LI, G., SU, Y., JI, J., RIFFAT, S. \& ZHENG, H. 2012. Preliminary Ray Tracing and Experimental Study on the Effect of Mirror Coating on the 
Optical Efficiency of a Solid Dielectric Compound Parabolic Concentrator. Energies, 5, 3627-3639.

RABL, A., O'GALLAGHER, J. \& WINSTON, R. 1980. Design and test of nonevacuated solar collectors with compound parabolic concentrators. Solar Energy, 25, 335-351.

RÖNNELID, M., PERERS, B. \& KARLSSON, B. 1997. On the factorisation of incidence angle modifiers for CPC collectors. Solar Energy, 59, 281-286.

SABRY, M., ABDEL-HADI, Y. A. \& GHITAS, A. 2013. PV-integrated CPC for transparent façades. Energy and Buildings, 66, 480-484.

SELLAMI, N. \& MALLICK, T. K. 2013. Optical characterisation and optimisation of a static Window Integrated Concentrating Photovoltaic system. Solar Energy, 91, 273-282.

SU, Y., KHAN, N., RIFFAT, S. B. \& GARETH, O. 2012a. Comparative monitoring and data regression of various sized commercial lightpipes. Energy and Buildings, 50, 308-314.

SU, Y., RIFFAT, S. B. \& PEI, G. 2012b. Comparative study on annual solar energy collection of a novel lens-walled compound parabolic concentrator (lens-walled CPC). Sustainable Cities and Society, 4, 35-40.

WELFORD, W. T. \& WINSTON, R. 1978. The optics of nonimaging concentrators: light and solar energy, Academic Press.

WITTKOPF, S., OLIVER GROBE, L., GEISLER-MORODER, D., COMPAGNON, R., KÄMPF, J., LINHART, F. \& SCARTEZZINI, J.-L. 2010. Ray tracing study for non-imaging daylight collectors. Solar Energy, 84, 986-996.

YU, X., SU, Y., ZHENG, H. \& RIFFAT, S. 2014a. A study on use of miniature dielectric compound parabolic concentrator (dCPC) for daylighting control application. Building and Environment, 74, 75-85.

YU, Y., LIU, N. \& TANG, R. 2014b. Optical performance of CPCs for concentrating solar radiation on flat receivers with a restricted incidence angle. Renewable Energy, 62, 679-688.

ZACHAROPOULOS, A., EAMES, P. C., MCLARNON, D. \& NORTON, B. 2000. Linear Dielectric Non-Imaging Concentrating Covers For PV Integrated Building Facades. Solar Energy, 68, 439-452. 